\title{
Cholesterol and Ion Channels
}

\author{
Irena Levitan, Yun Fang, Avia Rosenhouse-Dantsker, and Victor Romanenko
}

\begin{abstract}
A variety of ion channels, including members of all major ion channel families, have been shown to be regulated by changes in the level of membrane cholesterol and partition into cholesterol-rich membrane domains. In general, several types of cholesterol effects have been described. The most common effect is suppression of channel activity by an increase in membrane cholesterol, an effect that was described for several types of inwardly-rectifying $\mathrm{K}^{+}$channels, voltage-gated $\mathrm{K}^{+}$channels, $\mathrm{Ca}^{+2}$ sensitive $\mathrm{K}^{+}$channels, voltage-gated $\mathrm{Na}^{+}$channels, $\mathrm{N}$-type voltage-gated $\mathrm{Ca}^{+2}$ channels and volume-regulated anion channels. In contrast, several types of ion channels, such as epithelial amiloride-sensitive $\mathrm{Na}^{+}$channels and Transient Receptor Potential channels, as well as some of the types of inwardly-rectifying and voltage-gated $\mathrm{K}^{+}$channels were shown to be inhibited by cholesterol depletion. Cholesterol was also shown to alter the kinetic properties and current-voltage dependence of several voltage-gated channels. Finally, maintaining membrane cholesterol level is required for coupling ion channels to signalling cascades. In terms of the mechanisms, three general mechanisms have been proposed: (i) specific interactions between cholesterol and the channel protein, (ii) changes in the physical properties of the membrane bilayer and (iii) maintaining the scaffolds for proteinprotein interactions. The goal of this review is to describe systematically the role of cholesterol in regulation of the major types of ion channels and to discuss these effects in the context of the models proposed.
\end{abstract}

\section{Keywords}

Ion channels; Cholesterol; Lipid rafts

\subsection{Introduction}

During the last decade, a growing number of studies have demonstrated that the level of membrane cholesterol is a major regulator of ion channel function (reviewed by Maguy et al., 2006; Martens et al., 2004). It is also becoming increasingly clear that the impact of cholesterol on different types of ion channels is highly heterogeneous. The most common effect is cholesterol-induced decrease in channel activity that may include decrease in the open probability, unitary conductance and/or the number of active channels on the membrane. This effect was observed in several types of $\mathrm{K}^{+}$channels, voltage-gated $\mathrm{Na}^{+}$and $\mathrm{Ca}^{+2}$ channels, as well as in volume-regulated anion channels. However, there are also several types of ion channels, such as epithelial $\mathrm{Na}^{+}$channels $(\mathrm{eNaC})$ and transient receptor potential (Trp) channels that are inhibited by the removal of membrane cholesterol. Finally, in some cases changes in membrane cholesterol affect biophysical properties of the channel such as the voltage dependence of channel activation or inactivation. Clearly, therefore, more than one mechanism has to be involved in cholesterol-induced regulation of different ion channels.

\footnotetext{
(C) Springer Science+Business Media B.V. 2010

Department of Medicine, Pulmonary Section, University of Illinois at Chicago, 840 S. Wood Str, 60612, Chicago, IL, USA, levitan@uic.edu.
} 
Two general mechanisms have been proposed for cholesterol regulation of ion channels. One possibility is that cholesterol may interact directly and specifically with the transmembrane domains of the channels protein. Direct interaction between channels and cholesterol as a boundary lipid was first proposed in a "lipid belt" model by Marsh and Barrantes (1978) suggesting that cholesterol may be a part of a lipid belt or a "shell" constituting the immediate perimeter of the channel protein (Barrantes, 2004; Criado et al., 1982; Marsh and Barrantes, 1978). Figure 19.1 schematically shows the dynamic exchange between the lipid shell of an acetylcholine receptor protein and the bulk of the membrane (Barrantes, 2004). The role of cholesterol in the regulation of acetylcholine receptor is described in detail in Chapter 17 of this book. More recently, our studies demonstrated that inwardly-rectifying $\mathrm{K}^{+}$channel are sensitive to the chiral nature of the sterol analogue providing further support for the hypothesis that sensitivity of these channels to cholesterol can be due to specific sterol-protein interactions (Romanenko et al., 2002). An alternative mechanism proposed by Lundbaek and colleagues (Lundbaek and Andersen, 1999; Lundbaek et al., 1996) suggested that cholesterol may regulate ion channels by hydrophobic mismatch between the transmembrane domains and the lipid bilayer. More specifically, it was proposed that when a channel goes through a change in conformation state within the viscous medium of the lipid membrane it may induce deformation of the lipid bilayer surrounding the channel. If this is the case, then a stiffer less deformable membrane will increase the energy that is required for the transition, as described schematically in Fig. 19.2. It is important to note that the two mechanisms are not mutually exclusive. A lipid shell surrounding a channel may also affect the hydrophobic interactions between the channels and the lipids and increase the deformation energy required for the transitions between closed and open states. Finally, obviously, cholesterol may also affect the channels indirectly through interactions with different signalling cascades.

Another important factor in understanding the mechanisms of cholesterol regulation of ion channels is the association of the channels with cholesterol-rich membrane domains, typically called membrane or lipid rafts. While the exact nature and composition of these domains remains controversial, they are generally defined as "small $(10-200 \mathrm{~nm})$, heterogeneous, highly dynamic, sterol- and sphingolipid-enriched domains that compartmentalize cellular processes" (Pike, 2006). Indeed, a variety of ion channels have been shown to be associated with these domains. It is important to note, however, that within lipid rafts, channels may be regulated by any of the mechanisms described above: (i) by direct binding of cholesterol, which is abundant in the rafts; (ii) by an increase in membrane stiffness within the raft domains, also known as "ordered domains" due to high order of lipid packing and, of course (iii) by the interactions with multiple signalling molecules that are segregated within the raft domains. Thus, association with lipid rafts provides an additional level of complexity to how ion channels or any other membrane proteins can be regulated by cholesterol rather than a specific mechanism. In this chapter, we will systematically describe what is known about the effects of cholesterol on all major types of ion channels and discuss these effects in context of the three mechanisms described above.

We will also discuss the evidence for and the implications of cholesterol regulation of ion channels under hypercholesterolemic conditions in vivo. Indeed, the presence of high levels of cholesterol in the blood, termed hypercholesterolemia, contributes significantly to the development of many human cardiovascular diseases such as coronary heart disease and stroke. Human hypercholesterolemia is typically associated with diet and genetic factors, or can be direct result of other disorders such as diabetes mellitus and an underactive thyroid. Furthermore, hypercholesterolemia was shown to cause dysfunction of many cell types including endothelial cells, endothelial progenitor cells, smooth muscle cells, monocytes, macrophage, $\mathrm{T}$ lymphocytes, platelets and cardiomyocytes. In this chapter, we will therefore also discuss the current understanding of ion channel modulation by in vivo 
hypercholesterolemia that may underlie key mechanistic events of development of human diseases.

\subsection{Cholesterol Regulation of K+ Channels}

$\mathrm{K}^{+}$channels are a highly heterogeneous group constituting the largest and the most diverse group of ion channels that includes several structurally different classes, such as twotransmembrane domains inwardly-rectifying $\mathrm{K}^{+}$channels (Kir), four-transmembrane domains two pore $\mathrm{K}^{+}(2 \mathrm{PK})$ channels, and six-transmembrane domains voltage-gated $(\mathrm{Kv})$ and $\mathrm{Ca}^{+2}$ activated $\mathrm{K}^{+}\left(\mathrm{K}_{\mathrm{Ca}}\right)$ channels. Changes in the level of membrane cholesterol were shown to regulate multiple types of $\mathrm{K}^{+}$channels belonging to Kir, $\mathrm{Kv}$ and $\mathrm{K}_{\mathrm{Ca}}$ families. However, specific cholesterol effects vary significantly between different families or even between the members of the same family. The following section summarizes the similarities and the differences in cholesterol sensitivity of different types of $\mathrm{K}^{+}$channels.

\subsubsection{Inwardly Rectifying K+ (Kir) Channels}

Kir channels constitute one of the major classes of $\mathrm{K}^{+}$channels that are responsible for the maintenance of membrane potential and $\mathrm{K}^{+}$homeostasis in a variety of cell types, including heart, brain, vascular cells and pancreas (Bichet et al., 2003; Kubo et al., 2005; Nichols and Lopatin, 1997). Kir channels open at resting membrane potential and their main physiological roles is regulating membrane excitability, heart rate and vascular tone (Bichet et al., 2003; Kubo et al., 2005; Nichols and Lopatin, 1997). Structurally, Kir channels are tetramers with a basic subunit consisting of two transmembrane domains, a pore loop, and an $\mathrm{N}$-terminus and a C-terminus cytoplasmic domain. Kir channels are classified into seven sub-families (Kir17) identified by distinct biophysical properties, such as degree of current rectification and unitary conductance, and by their sensitivities to different mediators (reviewed by Kubo et al., 2005; Nichols and Lopatin, 1997). Three of these sub-families, Kir2, Kir4 and Kir6 channels, have been shown to be sensitive to cholesterol, but the ways cholesterol affects different types of Kir channels are significantly different. Cholesterol sensitivity of other Kir channels has not yet been established.

\subsubsection{Kir2 Channels}

Kir2 channels are ubiquitously expressed in a variety of cell types, including heart, neurons, vascular smooth muscle and endothelial cells (Kubo et al., 2005). Todate, four members of the Kir2 family have been identified (Kir2.1-2.4). All four members of the Kir2 family are suppressed by the elevation of membrane cholesterol and enhanced by cholesterol depletion, but there are some differences in their cholesterol sensitivity, with Kir2.1 and Kir2.2 being most sensitive and Kir2.3 being least sensitive (Romanenko et al., 2004a; Romanenko et al., 2002). Surprisingly, in spite of 2-3 fold decrease in whole cell Kir 2 currents, no or little effect was observed in the single channel properties of the channels: unitary conductance was not affected at all and the open probability was decreased less than $10 \%$ (Romanenko et al., 2004a; Romanenko et al., 2002). Moreover, changes in membrane cholesterol have no effect either on Kir2.1 expression, as estimated by Western blot analysis and by immunostaining, or on its plasma membrane level, as estimated by tagging the extracellular domains of the channels (Romanenko et al., 2004a), as was described earlier (Zerangue et al., 1999). Taken together, these observations led us to the hypothesis that Kir2 channels exist in the plasma membrane in two modes: "active channels" that flicker between the closed and the open states with high open probability and "silent channels" that are stabilized in their closed state.

The first clue about the mechanism came from comparing the effects of cholesterol and of its optical isomer, epicholesterol (Romanenko et al., 2002). The two stereoisomers, native cholesterol (3 $\beta$-hydroxy-5-cholestene) and epicholesterol ( $3 \alpha$-hydroxy-5-cholestene) differ 
only in the rotational angle of the hydroxyl group at position 3 and are known to have similar effects on membrane ordering and lipid packing (Demel et al., 1972; Xu and London, 2000). However, our observations showed that the effects of the two sterols on Kir2 channels are completely different: while, as described above, cholesterol suppresses Kir2 channels, partial substitution of native cholesterol by epicholesterol resulted in significant increase in Kir2 current suggesting that it is a specific lipid-channel interaction rather than changes in the physical properties of the membrane that is responsible for cholesterol-induced suppression of Kir2 channels (Fig. 19.3).

More recently, we have identified a specific region of the Kir2.1 channels that plays a critical role in the sensitivity of these channels to cholesterol (Fig. 19.4) (Epshtein et al., 2009).

Surprisingly, the region critical for the sensitivity of Kir2 channels to cholesterol was identified not in the transmembrane domain of the channels, as expected, but in the $\mathrm{C}$ terminus cytosolic domain. More specifically, cholesterol sensitivity of Kir2 channels depends on the CD loop, a specific region of the C-terminus of the cytosolic domain of the channel. Within this loop, the L222I mutation in Kir2.1 abrogates the sensitivity of the channel to cholesterol, whereas a reverse mutation in the corresponding position in Kir2.3, I214L, has the opposite effect, increasing cholesterol sensitivity. Furthermore, the L222I mutation has a dominant negative effect on cholesterol sensitivity of Kir2.1 WT. Mutations of two additional residues in the CD loop in Kir2.1, N216D and K219Q, partially affect the sensitivity of the channel to cholesterol. We proposed, therefore, that the residues of the CD-loop are involved in "docking" of the Cterminus of Kir2.1 to the inner leaflet of the membrane and facilitating its interaction with membrane cholesterol. In this model, when a channel is in the "docking" configuration it may interact with cholesterol, which in turn is proposed to stabilize the channel in a closed state. It is important to note, however, that in the framework of this hypothesis, the critical residues of the CD loop do not necessarily interact with cholesterol directly. Alternatively, it is possible that their role is to maintain the channels in a "docking" conformation state that allows cholesterol to bind to another part of the channel. Finally, it is also possible that residues in the CD-loop facilitate the hydrophobic interaction between the TM domains of the channel and the lipid core of the plasma membrane.

\subsubsection{Kir3 Channels}

Kir3 channels are a family of G-protein gated channels activated by $\mathrm{G}$ protein $\beta \gamma$ subunits and play a major role in the inhibitory regulation of neuronal excitability (Kir3.2 and Kir 3.1/3.2 heteromers) and in the regulation of the heart rate (Kir3.4, Kir3.1/3.4 heteromers) (Kubo et al., 2005). Loss of Kir3 channels leads to hyperexcitability in the brain, hyperactivity and seizures, as well as cardiac abnormalities. Little is known, however, about cholesterol sensitivity of these channels. Specifically, it was shown that regulation of Kir3.1/3.2 channels by Neural Cell Adhesion Molecule (NCAM) was compromised by lovastatin, a drug that lowers cholesterol (Delling et al., 2002). It was also shown that deletion of a number of genes that have been shown to alter the lipid composition of yeast membrane significantly affect functional expression of Kir3.2 channels in the yeast membranes, suggesting that membrane lipids may play an important role in the regulation of Kir3.2 trafficking and/or function (Haass et al., 2007). Clearly, more studies are needed to investigate how cholesterol affects Kir3 channels.

\subsubsection{Kir4 Channels}

Kir4 channels are also expressed in multiple cell types, including glial and kidney epithelial cells. Two Kir4 channels have been identified: Kir4.1 implicated in the control of $\mathrm{K}^{+}$buffering and homeostasis, and Kir4.2 whose physiological functions are not well established yet (Kubo et al., 2005). Recently, (Hibino and Kurachi, 2007) have shown that Kir4.1 channels are cholesterol sensitive, but in contrast to Kir2 channels, Kir4.1 channels were shown to be inhibited by cholesterol depletion. Furthermore, the authors suggested that the loss of Kir4.1 
activity may be due to the dissociation of the channels from a regulatory phospholipid $\operatorname{PI}(4,5)$ P2 that is known to be required for the activation of multiple ion channels including Kir channels (Hilgemann et al., 2001; Logothetis et al., 2007), that also resides in cholesterol-rich membrane domains (Pike and Casey, 1996). This interpretation, however, does not explain the dramatic difference between Kir4.1 and Kir2 channels in terms of their sensitivity to cholesterol because Kir2 also require PI(4,5)P2 for their function. The source of this difference is not yet clear.

\subsubsection{Kir6 (K}

Kir6 ( $\left.\mathrm{K}_{\mathrm{ATP}}\right)$ channels are heteromultimeric Kir channels with a pore formed by a tetramer of Kir6 subunits with each Kir6 subunit associated with one ATP-binding cassette (ABC) sulfonylurea receptor (SUR) protein (reviewed by Nichols, 2006; Zingman et al., 2007). Two members of the Kir6 channel family have been identified: Kir6.1 channels are expressed in vascular smooth muscle cells and Kir6. 2 channels in pancreatic $\beta$-cells, heart, and brain (Kubo et al., 2005; Nichols, 2006; Zingman et al., 2007). It is known that $\mathrm{K}_{\mathrm{ATP}}$ channels are under the control of protein kinases A (PKA) and C (PKC), with PKA activating the channels and PKC having an inhibitory effect (Edwards and Weston, 1993). Sampson and colleagues (Sampson et al., 2007; Sampson et al., 2004) showed that cholesterol depletion affects Kir6.1 by interfering with the coupling of the channels to PKA, thus inhibiting PKA-dependent activation of the channels.

\subsection{Association of Kir Channels with Cholesterol-Rich Membrane Domains (Lipid Rafts)}

As discussed briefly above, multiple studies have shown that different types of ion channels are associated with lipid rafts. Indeed, members of almost all of the Kir families were shown to partition into cholesterol-rich membrane domains: Kir2 s (Kir2.1 and Kir2.3) (Tikku et al., 2007), Kir3.1/3.4 (Delling et al., 2002), Kir 4 (Hibino and Kurachi, 2007) and Kir6.1 (Sampson et al., 2004). However, partitioning of different Kir channels into lipid rafts may be associated with completely different or even opposite functional effects: for example, Kir2 channels are suppressed by cholesterol whereas Kir 4 channels are suppressed by cholesterol depletion. The variability of these effects may be due to specific raft environments or due to structural differences between the channels. Furthermore, we have shown recently that Kir2.1-L222I mutant that is not sensitive to cholesterol also partitions into lipid rafts (Epshtein et al., 2009), demonstrating that partitioning into rafts does not necessarily indicate that the channels are functionally regulated by changes in membrane cholesterol. Thus, while partitioning into cholesterol-rich membrane domains is frequently associated with functional dependence of ion channels on membrane cholesterol, it is not always the case. Furthermore, within the rafts, channels may be regulated by completely different mechanisms.

\subsubsection{Regulation of Kir Channels by Plasma Hypercholesterolemia In Vivo}

Kir2: Our group has demonstrated that diet-induced hypercholesterolemia in a porcine model results in significant suppression of Kir current in freshly-isolated aortic endothelial cells and in bone-marrow derived progenitor cells (Fang et al., 2006; Mohler Iii et al., 2007). Removing cholesterol surplus ex vivo resulted in full recovery of the current. We have also shown previously that endothelial Kir current is underlain by Kir2.1 and Kir2.2 channels (Fang et al., 2005). In addition, hypercholesterolemia resulted in significant membrane depolarization of endothelial cells and notable loss of flow-mediated vasodilatation of the femoral artery estimated in vivo in the same model (Fang et al., 2006). We proposed that since endothelial Kir channels are sensitive to shear stress and constitute one of the putative flow sensors (Davies, 1995; Olesen et al., 1988), impairment of flow-induced vasodilatation may be due to the suppression of endothelial Kir channels (Fang et al., 2006). These observations suggest that 
hypercholesterolemia-mediated suppression of Kir channels may be an important factor in dysfunction of mature endothelium and endothelial progenitor cells and contribute to the initiation and development of atherosclerosis.

Kir6 ( $\left.\mathrm{K}_{\mathrm{ATP}}\right)$ channels are also regulated by hypercholesterolemia in vivo, but the mode of the regulation is still controversial. In a porcine model, (Mathew and Lerman, 2001) showed that pinacidil, a $\mathrm{K}_{\mathrm{ATP}}$ opener, and glibenclamide, a $\mathrm{K}_{\mathrm{ATP}}$ blocker, have stronger effects on coronary blood flow under hypercholesterolemic conditions than under control conditions, suggesting functional activation of Kir6 under hypercholesterolemia. In contrast, Genda et al. (2002) demonstrated that diet-induced hypercholesterolemia suppressed $\mathrm{K}_{\mathrm{ATP}}$ opening in microvasculature, which led to a delay of infarct healing under no-reflow phenomenon after acute myocardial infarction in a rabbit model. Lee et al. (2004) also reported that hypercholesterolemia resulted in impairment of myocardial $\mathrm{K}_{\mathrm{ATP}}$ channels, which contributed to left ventricular hypertrophy in a rabbit model. One possibility to account for these differences in the effects of hypercholesterolemia on $\mathrm{K}_{\mathrm{ATP}}$ activity may be the difference in the lipid profiles between hypercholesterolemic rabbits and pigs. Pongo et al. (2001) reported dysfunction of protein kinase $\mathrm{C}-\mathrm{K}_{\mathrm{ATP}}$ channel coupling in rabbit coronary arteries under hypercholesterolemia, providing a mechanistic explanation of hypercholesterolemia-induced suppression of $\mathrm{K}_{\mathrm{ATP}}$ activity. Hypercholesterolemia may also regulate Kir channels on the level of mRNA expression. Ren et al. (2001) demonstrated that hypercholesterolemia enhanced the mRNA of Kir6.2, but down-regulated Kir3.1 mRNA in smooth muscle cells while Kir2.1 and Kir6.1 transcripts were unchanged in a rat model.

In summary, sensitivity to cholesterol and association with cholesterol-rich membrane domains appears to be a common feature for multiple types of Kir channels but there is a strong diversity in the effects of cholesterol on channel function, and while some Kir channels, specifically Kir2 s, are suppressed by cholesterol, other Kirs, specifically Kir4.1, require cholesterol for their function. Our recent studies provided the first insights into the structural requirements for cholesterol sensitivity of Kir2 channels, establishing the basis for further investigations and detailed understanding of how Kir channels interact with cholesterol. Furthermore, we propose that suppression of Kir channels in hypercholesterolemic conditions may play a major role in the development of cardiovascular disease.

\subsection{Voltage-Gated $\mathrm{K}^{+}(\mathrm{Kv})$ Channels}

Voltage-gated $\mathrm{K}^{+}$channels are the largest and the most diverse family of $\mathrm{K}^{+}$channels that include about 40 members, classified into 12 subfamilies (Kv1-12 sub-families) (Gutman et al., 2005). Kv channels open in response to membrane depolarization and their main physiological role is termination of action potentials and returning of the membrane potential back to its resting state. A large diversity of $\mathrm{Kv}$ channels with different activation and inactivation properties underlie the plethora of firing patterns in different excitable cells. $\mathrm{Kv}$ channels are also expressed in a variety of non-excitable cells, including different types of immune cells where they are known to play important roles in the immune response. Structurally, Kv channels are tetramers formed either of identical subunits or between different $\mathrm{Kv}$ subunits with each subunit consisting of 6 transmembrane helices (S1-S6) linked by extracellular and cytosolic loops. The fifth and the sixth helices (S5-S6) and the connecting pore region form the conducting pore and are homologous to the two transmembrane helices of Kir channels (Gutman et al., 2005). Several types of Kv channels belonging to different subfamilies have been identified in lipid rafts and shown to be sensitive to changes in the level of membrane cholesterol, but molecular mechanisms underlying cholesterol sensitivity of $\mathrm{Kv}$ channels are mostly unknown. 


\subsubsection{Kv1 Channels}

Kc1 channels constitute the Shaker-related family of delayed rectifiers consisting of eight members (Kv1.1-1.8) expressed in brain, heart, skeletal muscle, pancreas and blood cells (Gutman et al., 2005). The role of cholesterol in regulation of Kv1 channels was investigated mainly for two members of the family, Kv1.3 and Kv1.5, but specific effects observed in different studies are highly controversial. $\underline{K v 1.3}$ is expressed in a variety of cell types and plays a critical role in the regulation of membrane potential and calcium signalling and apoptosis of T lymphocytes (Bock et al., 2003; Gutman et al., 2005; Hajdú et al., 2003). (Bock et al., 2003) showed that Kv1.3 partition almost exclusively to cholesterol-rich membrane domains in a T-lymphocytes cell line and that cholesterol depletion significantly decreases Kv1.3 activity. However, (Hajdú et al., 2003) observed an opposite effect in primary lymphocytes. Specifically, (Hajdú et al., 2003) showed that elevation of membrane cholesterol in primary lymphocytes resulted in a significant decrease in Kv1.3 current density, slowing down both activation and inactivation kinetics and the right-shift in the voltage dependence of activation. These changes are consistent with a decrease in the open probability of the channels upon cholesterol loading. In terms of partitioning into lipid rafts, Kv1.3 was demonstrated to cluster with a $\mathrm{T}$ cell antigen receptor complex (Panyi et al., 2003) and localize to the immunological synapse where it also colocalizes with a lipid raft marker $\mathrm{G}_{\mathrm{M} 1}$ (Panyi et al., 2004). Kv1.3 also partitions into lipid rafts when expressed heterologously in HEK cells (Vicente et al., 2008) but its membrane distribution is uniform rather than clustered (O'Connell et al., 2004), which may be consistent with partitioning into small but highly abundant lipid rafts. Kv1.4 channels were also shown to partition to lipid rafts in neurons (Wong and Schlichter, 2004), but not in pancreatic $\beta$-cells (Xia et al., 2004). $\underline{K v 1.5}$, a channel that underlies an ultrarapid-activating $\mathrm{K}^{+}$current in heart muscle (Gutman et al., 2005) is also significantly affected by cellular cholesterol. First, (Martens et al., 2001) showed that cholesterol depletion resulted in a hyperpolarizing shift in the voltage dependence of both activation and inactivation of the current, which would be expected to have a significant impact on the duration of action potentials that are controlled by Kv1.5 channels. More recently, Abi-Char et al. (2007) showed that cholesterol depletion results in a slow progressive increase of the Kv1.5-based component of the ultrarapid delayed rectifier current $\left(\mathrm{I}_{\mathrm{Kur}}\right)$ in atrial cardiomyocytes. Kv1.5 was also shown to partition into lipid rafts but the relative distribution between rafts and non-rafts, as well as association of the channels with caveolae are still controversial and may vary in different cells and in different experimental conditions (Abi-Char et al., 2007; Eldstrom et al., 2006; Martens et al., 2001; McEwen et al., 2008; Vicente et al., 2008).

\subsubsection{Kv2 Channels}

Kv2 channels are the Shab-related family of delayed rectifiers consisting of two members $\mathrm{Kv} 2.1$ and $\mathrm{Kv} 2.2$, both playing key roles in the regulation of neuron excitability (Gutman et al., 2005). Kv2.1 was the first member of the Kv family to be found in lipid rafts and identified as sensitive to membrane cholesterol (Martens et al., 2000; Xia et al., 2004). More specifically, $\mathrm{Kv} 2.1$ partitions into non-caveolae lipid rafts and its membrane distribution is significantly different from that of Kv1 channels: Kv2.1 channels appear as clusters and have very limited lateral mobility whereas Kv1.3 and Kv1.4 were distributed more homogenously and were significantly more mobile (O'Connell et al., 2004). More recently, distinct cellular distributions of Kv2.1 and Kv1.4 were also demonstrated in freshly-isolated cardiomyocytes (O'Connell et al., 2008). Clustering of Kv2.1 channels was also significantly different in atrial and ventricular myocytes providing additional evidence that sub-cellular organization of $\mathrm{Kv}$ channels is cellspecific, which again may underlie the variability of cholesterol effects observed in different cell types (O'Connell et al., 2008). Interestingly, cholesterol depletion resulted in a significant increase in Kv2.1 cluster size (O'Connell et al., 2004), an effect quite unexpected because cholesterol depletion is typically believed to disrupt protein complexes in raft domains. The effect of cholesterol depletion on Kv2.1 mobility was also significantly different from its effect 
on Kv1.3 and Kv1.4. These observations suggest that all three channels partition into distinct types of lipid rafts, which may also explain the differences in their functional dependence on cholesterol depletion. Functionally, cholesterol depletion resulted in a significant hyperpolarizing shift of Kv2.1 inactivation from $\mathrm{V}_{1 / 2}$ of $\sim-16 \mathrm{mV}$ to $\sim-52 \mathrm{mV}$ (Martens et al., 2000). However, Xia et al. (2004) showed that in pancreatic $\beta$-cells, the Kv2.1 current is strongly suppressed by $\mathrm{M} \beta \mathrm{CD}$-induced cholesterol depletion. While the difference between the two observations is not clear, it was suggested to be due to possible differences in the microenvironment between rafts in insulin-secreting cells and in mouse L cells. Additionally, cholesterol depletion was shown to increase voltage-gated $\mathrm{K}^{+}$current in Drosophila neurons (Kenyon cells), the current that is putatively underlain by the Shab gene, a Drosophila homolog of Kv2.1 (Gasque et al., 2005). The reasons for these differences are not clear and may reflect the diversity of specific lipid environments and/or association of the channels with different regulatory subunits.

\subsubsection{Other Kv Channels}

$K v 3$ channels constitute a Shaw-related family that consists of four members (Kv3.1-3.4) (Gutman et al., 2005). Kv3.2 and Kv3.3 were shown to partition into non raft fractions in pancreatic $\alpha$-cells (Xia et al., 2007). Kv4 are a Shal-related family of $\mathrm{Kv}$ channels that includes three members (Kv4.1-4.3) (Gutman et al., 2005). All three members of the Kv4 family were shown to partition into lipid rafts in some (Wong and Schlichter, 2004; Xia et al., 2007), but not all studies (Martens et al., 2000). Thus, functional dependence of Kv4 channels on membrane cholesterol is not yet established. Two more types of Kv channels, Kv7.1 (KCNQ) and Kv11.1 (hERG1) were also found to partition into rafts (Balijepalli et al., 2006). Cholesterol depletion results in a positive shift in the voltage dependence of activation and acceleration of the deactivation rate of Kv11.1 channels, both when the channels are expressed in HEK cells and in mouse myocytes (Balijepalli et al., 2006).

\subsubsection{Regulation of Kv Channels by Plasma Hypercholesterolemia}

Several studies have shown that plasma hypercholesterolemia has a major impact on the function of Kv channels. First, Jiang et al. (1999) reported that opening of Kv channels in aortic smooth muscle cells is significantly reduced in a hypercholesterolemic mouse model that lacks apolipoprotein E (Apo E) and low density lipoprotein receptor genes (LDLR (Apo E ${ }^{-}$) LDLR $^{-}$mice). Consistently, Ghanam et al. (2000) demonstrated that 4-aminopyridine, a blocker of voltage-dependent $\mathrm{K}^{+}$channels, strongly inhibited the acetylcholine-induced relaxation in normal rabbit cerebral arteries but not in cholesterol-fed rabbits, indicating impairment of $\mathrm{Kv}$ channel-mediated vasodilation under hypercholesterolemia. Finally, Heaps et al. (2005) showed that $\mathrm{Kv}$ channel-mediated, adenosine-induced vasodilatation was impaired in coronary arterioles of hypercholesterolemic pigs and that $\mathrm{Kv}$ currents in coronary arteriolar smooth muscle cells were significantly reduced. This, hypercholesterolemia impairs $\mathrm{Kv}$ channel activity in vascular smooth muscle cells and the consequent $\mathrm{Kv}$ channel-mediated cellular function in the cardiovascular system. The impact of hypercholesterolemia on other types of $\mathrm{Kv}$ channels has not yet been established.

In Summary, multiple types of $\mathrm{Kv}$ channels have been found to partition into lipid rafts but, similar to Kir channels, the functional impact of cholesterol on the activity and biophysical properties of different $\mathrm{Kv}$ channels appear to be highly variable. One of the important insights of these studies is the discovery that different types of $\mathrm{Kv}$ channels may partition into distinct types of membrane domains in the same cells (Fig. 19.5) (Martens et al., 2000; Martens et al., 2001; O'Connell and Tamkun, 2005). It is also clear that cholesterol-dependent changes in the voltage characteristics of $\mathrm{Kv}$ channels are expected to have major impacts on the termination of action potentials and firing patterns of a variety of excitable cells. 


\section{5 $\mathrm{Ca}^{2+-}$-Activated $\mathrm{K}^{+}$Channels}

Three families of $\mathrm{Ca}^{2+}$-activated $\mathrm{K}^{+}$channels are recognized on the basis of their genetic, biophysical, and pharmacologic properties: large ( $\mathrm{BK}, \mathrm{K}_{\mathrm{Ca}} 1.1$, maxi-K, or Slo), intermediate (IK, $\mathrm{K}_{\mathrm{Ca}} 3.1$ ) and small ( $\mathrm{SK}, \mathrm{K}_{\mathrm{Ca}} 2$ ) conductance channels. In addition to the well known $\mathrm{Ca}^{2+}$-activated $\mathrm{K}_{\mathrm{Ca}} 1.1$, the large conductance $\mathrm{K}^{+}$channel family also includes the homologous $\mathrm{Na}^{+}$activated $\mathrm{K}_{\mathrm{Ca}} 4.1$ and $\mathrm{K}_{\mathrm{Ca}} 4.2$ channels (Slack and Slick, respectively) and the $\mathrm{pH}$-sensitive $\mathrm{K}_{\mathrm{Ca}} 5.1$ channel (Salkoff et al., 2006). The ubiquitous ${ }_{{ }_{\mathrm{Ca}}} 1.1$ channel controls a diverse array of physiological functions including the regulation of smooth muscle tone (Khan et al., 2001; Sprossmann et al., 2009), the excitability of neurons (Sah and Faber, 2002) and electrolyte secretion in the salivary glands and colon (Perry and Sandle, 2009; Romanenko et al., 2007). $\mathrm{K}_{\mathrm{Ca}} 4$ channels are found in the brain and in several types of myocytes (Bhattacharjee and Kaczmarek, 2005), and expression of $\mathrm{K}_{\mathrm{Ca}} 5$ is restricted to the testis (Santi et al., 2009; Schreiber et al., 1998). The intermediate-conductance $\mathrm{K}_{\mathrm{Ca}} 3.1$ channels are primarily expressed in nonexcitable cells and are involved in many physiological functions ranging from red blood cell volume regulation (Begenisich et al., 2004; Vandorpe et al., 1998) to mitogen activation of Tlymphocytes (Ghanshani et al., 2000; Logsdon et al., 1997). SK channels play an important role in neuronal excitability and function in the CNS and periphery (Bond et al., 1999; Bond et al., 2005). Additionally, several $\mathrm{Ca}^{2+}$-activated $\mathrm{K}^{+}$channels are expressed in vascular smooth muscles and endothelium and are important for regulation of vascular functions (Feletou, 2009; Ledoux et al., 2006).

\subsubsection{BK}

Among the large-conductance $\mathrm{K}^{+}$channels, only $\mathrm{K}_{\mathrm{Ca}} 1.1$ has been reported to be sensitive to the membrane cholesterol level. Cholesterol-dependent regulation of $\mathrm{K}_{\mathrm{Ca}} 1.1$ current varies dramatically, from strong suppression to upregulation, depending on the cell or tissue type studied. The inhibitory effect of cholesterol on $\mathrm{K}_{\mathrm{Ca}} 1.1$ currents or, alternatively, current upregulation by cholesterol level reduction has been demonstrated in endothelial (Wang et al., 2005), smooth muscle (Bolotina et al., 1989; Brainard et al., 2005), neuronal (Lin et al., 2006) cells and colonic epithelia (Lam et al., 2004). This cholesterol-dependent inhibition is likely to be due to changes in the open probability and not in the unitary conductance of the channel (Bolotina et al., 1989; Chang et al., 1995; Crowley et al., 2003; Lin et al., 2006; Yuan et al., 2004). Conversely, downregulation of the channel by lowering the cholesterol level has been demonstrated in rat uterine myocytes and in glioma cell (Shmygol et al., 2007; Weaver et al., 2007). Finally, lack of any effect of cholesterol has been reported for heterologous expression of the $\alpha$ subunit of the channel cloned from rat brain (King et al., 2006) and for channels in parotid acinar cells (Romanenko et al., 2009). The latter study demonstrated that while the amplitude and the biophysical properties of $\mathrm{K}_{\mathrm{Ca}} 1.1$ and $\mathrm{K}_{\mathrm{Ca}} 3.1$ currents were not affected by cholesterol depletion, the functional interaction between the two channels was dependent on the membrane cholesterol.

Currently, no single mechanism rationalizing the diversity of cholesterol effects on $\mathrm{K}_{\mathrm{Ca}} 1.1$ channel has been proposed. Several studies suggested that the channel modulation is mainly due to changes in the biophysical properties of the lipid bilayer (Bolotina et al., 1989; Chang et al., 1995). The hypothesis was supported by cholesterol-dependent modulation of BK sensitivity to temperature changes, which is consistent with the known effects of cholesterol on lateral elastic stress within the lipid bilayer as a function of temperature (Chang et al., 1995). Crowley et al. (2003) found that cholesterol modulated the activity of the channels recon-stituted in bilayers composed of POPE/POPS mixture, but failed to do so in pure POPE bilayers. It has been hypothesized that cholesterol modulation of the bilayer stress energy was masked in pure POPE because of high initial degree of curvature stress. Interestingly, the same 
human $\mathrm{K}_{\mathrm{Ca}} 1.1$ channel $\alpha$-subunit expressed in HEK293 cells alone or in combination with any of the four known $\beta$ subunits was cholesterol-insensitive (King et al., 2006).

In several studies cholesterol-dependent modulation of the channel activity in native cellular membranes has been attributed to its localization to lipid rafts. Membrane fractionation methods and co-localization with the lipid raft marker caveolin has been used to demonstrate the association of the channels with the raft membrane microdomains. It was also demonstrated that cholesterol depletion or interfering with caveolin scaffolding or expression decreases raft association of the channels (Babiychuk et al., 2004; Brainard et al., 2005; Bravo-Zehnder et al., 2000; Shmygol et al., 2007; Wang et al., 2005; Weaver et al., 2007). While in most of these studies, destabilization of lipid rafts upregulated BK currents, Weaver et al (2007) showed that cholesterol depletion inhibits an intricate functional association of BK channels and $\mathrm{IP}_{3}$ receptors resulting in strong reduction of $\mathrm{K}^{+}$currents. Nevertheless, Lam et al. (2004) found that the cholesterol-sensitive $\mathrm{BK}$ channel is not present in low-density membrane fractions. Finally, Romanenko et al (2009) demonstrated that the interaction between $\mathrm{K}_{\mathrm{Ca}} 1.1$ and $\mathrm{K}_{\mathrm{Ca}} 3.1$ channels is cholesterol-dependent but does not require caveolin- 1 . This suggests that the participation of the channels in at least one type of lipid rafts, caveolae, is not required for the channel interaction. It is possible however, that other membrane domains are involved (e.g. flotillin-enriched microdomains (Langhorst et al., 2005).

BK channels were also shown to be sensitive to plasma hypercholesterolemia. First, earlier studies have shown that BK channels play a larger role in endothelium-dependent vasodilatation of carotid artery in hypercholesterolemic rabbits than in control animals (Najibi and Cohen, 1995; Najibi et al., 1994). It was suggested that an enhanced role of vascular BK channels under hypercholesterolemic conditions may be due to lower basal channel activity, in which case the availability of BK channels to acetylcholine stimulus may be increased (Sobey, 2001). In contrast, Jeremy and McCarron (2000) have shown that diet-induced hypercholesterolemia in rabbits significantly suppressed $\mathrm{K}_{\mathrm{Ca}}$-mediated vasodilatation in response to acetylcholine and bradikinin, as estimated by measuring hind limb vascular conductance. The effect was blocked by carybdotoxin, a blocker of BK channels. In addition, it was also shown that hypercholesterolemia decreases the expression of the BK $\beta 1$ subunit that sensitizes the BK channel to intracellular $\mathrm{Ca}^{2+}$ (Du et al., 2006). Interestingly, Wiecha et al. (1997) reported a significantly higher BK activity in human smooth muscle cells obtained from atherosclerotic plaques, compared to those isolated from control media segments of human coronary arteries. Thus, several lines of evidence suggest that BK activity is modulated by hypercholesterolemia in a tissue-specific way.

\subsubsection{SK and IK}

As mentioned above, $\mathrm{Ca}^{2+}$-activated $\mathrm{K}^{+}$channels are involved in regulation of a variety of vascular functions. Specifically, opening of SK and IK channels is a key step in endotheliumdependent hyperpolarization and relaxation of the vascular wall (Ledoux et al., 2006). Absi et al. (2007) demonstrated that cholesterol depletion of a vascular wall with intact epithelium resulted in SK-dependent vasorelaxation while IK-dependent hyperpolarization was unaffected. Moreover, the arterial SK but not IK channel protein was in low density membrane fraction and co-localized with caveolin-1 (Absi et al., 2007). Conversely, impairment of endothelium-dependent vasodilatation mediated by $\mathrm{Ca}^{2+}$-activated $\mathrm{K}^{+}$channels was observed in hind limb vasculature of hypercholesterolemic rabbits (Jeremy and McCarron, 2000). At the same time, Toyama et al. (2008) recently demonstrated up-regulation of $\mathrm{K}_{\mathrm{Ca}} 3.1$ expression in coronary vessels of patients with coronary artery disease. Furthermore, $\mathrm{K}_{\mathrm{Ca}} 3.1$ expression was also upregulated in smooth muscle cells, macrophages, and T lymphocytes found in atherosclerotic lesions of $\mathrm{ApoE}^{-1-}$ mice, one of the main genetic models of atherosclerosis (Toyama et al., 2008). These authors further demonstrated that increased IK activity plays a 
key role in regulating the proliferation, migration, ROS, and cytokine production in vascular cells, consequently contributing to atherogenesis. Application of IK blockers in $A p o E^{-/-}$mice markedly reduced the development of atherosclerosis, indicating IK as a novel therapeutic target for atherosclerosis under hypercholesterolemia. In contrast, expression of SK channels in aortas of hypercholesterolemic Apo $\mathrm{E}^{-/-}$mice was significantly reduced compared with wild-type controls (Zhou et al., 2007).

In Summary, similarly to the two groups of $\mathrm{K}^{+}$channels described above, while the effects of cholesterol on $\mathrm{Ca}^{2+}$-activated $\mathrm{K}^{+}$channels are complex and controversial, multiple lines of evidence demonstrate that cholesterol sensitivity of these channels may play an important role in the development of cardiovascular disease.

\subsection{Na+Channels}

\subsubsection{Voltage-Gated $\mathrm{Na}^{+}\left(\mathrm{Na}_{\mathrm{v}}\right)$ Channels}

Voltage-gated $\mathrm{Na}^{+}$channels are members of the same superfamily of ion channels as the voltage-gated $\mathrm{K}^{+}$channels described above (Catterall et al., 2005a). The pore forming $\alpha$ subunits of $\mathrm{Na}_{\mathrm{v}}$ channels consist of four domains, homologous to the basic subunit of the $\mathrm{Kv}$ channels with six transmembrane helices (S1-S6) (Catterall et al., 2005a). However, in contrast to the highly diverse $\mathrm{Kv}$ channels, $\mathrm{Na}_{\mathrm{v}}$ channels are relatively similar and contain only one family of channels consisting of nine members $\left(\mathrm{Na}_{\mathrm{v}} 1.1-1.9\right)$. The main physiological role of $\mathrm{Na}_{\mathrm{V}}$ channels is the initiation and propagation of action potentials in a variety of excitable cells including neurons, different types of muscle cells and neuroendocrine cells (Catterall et al., 2005a). Two general mechanisms have been described for cholesterol sensitivity of $\mathrm{Na}_{\mathrm{v}}$ channels: partitioning to caveolae (cardiac $\mathrm{Na}_{\mathrm{v}} 1.5$ channels) (Yarbrough et al., 2002) and regulation by the elastic properties of the membrane lipid bilayer (skeletal $\mathrm{Na}_{\mathrm{v}} 1.4$ channels) (Lundbaek et al., 2004). It was also shown that plasma hypercholesterolemia resulting in a $\sim 2$-fold increase in the level membrane cholesterol in rabbit ventricular myocytes is associated with a significant decrease in the current density of voltage-gated $\mathrm{Na}^{+}$currents (Wu et al., 1995). Specifically, plasma hypercholesterolemia resulted in decreased current density, slower recovery from inactivation, and more negative potential for inactivation of the sodium inward currents in hyperlipidemic myocytes (Wu et al., 1995).

One of the first studies to test the role of cholesterol in the regulation of voltagegated $\mathrm{Na}^{+}$ channels showed that cholesterol dramatically alters the sensitivity of $\mathrm{Na}_{\mathrm{v}}$ channels to pentobarbital (Rehberg et al., 1995). In this study, $\mathrm{Na}_{\mathrm{v}}$ channels were isolated from human cortical brain tissues and incorporated into PE/PC lipid bilayers with cholesterol added up to $50 \%$ weight/weight. An increase in cholesterol alone had no effect on the single channel properties of the channels, but it significantly inhibited the pentobarbital-induced block of the channels. Furthermore, competitive inhibition of the pentobarbital block was observed at very low concentrations of cholesterol with an $\mathrm{EC}_{50}$ of less than $2 \%$, which is below cholesterol levels found in neuronal cells (Rehberg et al., 1995). In terms of the mechanism, it was proposed that the competitive effect could be either due to changes in the physical properties of the lipid bilayer or due to a direct interaction with the channel or with the anesthetic. The first mechanism was investigated in more details for the skeletal $\mathrm{Na}_{\mathrm{v}} 1.4$ channels as described below.

$N a_{v} 1.4$ channels responsible for the initiation of transmission of action potentials in skeletal muscle (Catterall et al., 2005a) were also shown to be significantly dependent on membrane cholesterol when expressed in HEK cells (Lundbaek et al., 2004). Specifically, depletion of membrane cholesterol resulted in a significant hyperpolarizing shift in current inactivation, an effect that was partially reversible by cholesterol depletion. Cholesterol enrichment, on the other hand, had no effect on the inactivation of the current. Surprisingly, however, cholesterol enrichment did have a significant effect on the voltage parameters of current activation whereas 
cholesterol depletion had no effect. Cholesterol depletion also decreased the peak amplitude of the current. In this case, it was proposed that cholesterol sensitivity of voltage-gated $\mathrm{Na}^{+}$ channels can be attributed to the sensitivity of the channels rather than to the physical properties of the membrane bilayer because the effect of cholesterol depletion was similar to the effect induced by exposing the cells to $10 \mu \mathrm{M}$ Triton X-100 or $2.5 \mathrm{mM} \beta$-octyl-glucoside ( $\beta \mathrm{OG}$ ), two micelle-forming amphiphilic compounds which are known to alter the physical properties of the membrane lipid bilayer (Lundbaek et al., 2004). More specifically, (Lundbaek et al., 2004) proposed that $\mathrm{Na}_{\mathrm{v}} 1.4$ channels are regulated by the elastic properties of the membrane.

$N a_{v} 1.5$ channels are responsible for the initial upstroke of the action potential in atrial and ventricular myocytes, as well as contribute to the propagation of the action potential in the heart (Balijepalli and Kamp, 2008). $\mathrm{Na}_{\mathrm{v}} 1.5$ channels partition into cholesterol-rich membrane fractions and directly interact with caveolin-3 (Yarbrough et al., 2002). Furthermore, blocking the interaction with caveolin-3 using anti-caveolin antibodies abrogates direct $\mathrm{G}_{\mathrm{s}} \alpha$-mediated regulation of $\mathrm{Na}_{\mathrm{v}} 1.5$ current by $\beta$-adrenergic stimulation (Palygin et al., 2008; Yarbrough et al., 2002). It was proposed that activation of $\beta$-adrenergic activation of $\mathrm{G}_{\mathrm{s}} \alpha$ results in opening of the necks of the caveolae and thus recruiting caveolae $\mathrm{Na}_{\mathrm{v}} 1.5$ channels to the sarcolemma (Yarbrough et al., 2002). It was also proposed that caveolin-3 may directly stabilize the interaction between the channels and $\mathrm{G}_{\mathrm{s}} \alpha$ subunits (Palygin et al., 2008). While the role of cholesterol was not tested directly in these studies, multiple studies have shown that changes in the level of membrane cholesterol both in vitro and in vivo have profound effects on the integrity of caveolae, suggesting that $\beta$-adrenergic stimulation of cardiac $\mathrm{Na}_{\mathrm{v}} 1.5$ channels is cholesterol dependent.

\subsubsection{Epithelial $\mathrm{Na}^{+}$Channels (eNaC)}

Amiloride-sensitive $\mathrm{Na}^{+}$channels constitute another family of $\mathrm{Na}^{+}$channels expressed mostly in different types of epithelial cells (hence the name epithelial $\mathrm{Na}^{+}$channels, $\mathrm{eNaC}$ ), which are responsible for $\mathrm{Na}^{+}$absorption regulating $\mathrm{Na}^{+}$and fluid homeostasis, which in turn play important roles in the control of blood pressure (de la Rosa et al., 2000). eNaC channels are heteromultimeric proteins formed by pore-forming $\alpha$ subunits plus two regulatory subunits ( $\beta$ and $\gamma$ ) (de la Rosa et al., 2000). Several studies have shown that eNaC subunits partition into lipid rafts (Hill et al., 2002; Hill et al., 2007; Prince and Welsh, 1999), but in other studies eNaC was found not to associate with rafts (Hanwell et al., 2002). Hill et al. (2002) also showed that $\mathrm{M} \beta C \mathrm{CD}$-induced cholesterol depletion results in partial redistribution of $\beta$ and $\gamma$ subunits to higher density fractions, corresponding to a shift in the distribution of caveolin. It is noteworthy that a similar shift was observed in cells exposed to aldosterone, a hormone known to be involved in sodium channel regulation. More recently, it was also shown that $\mathrm{eNaC}$ directly interacts with caveolin-1 (Lee et al., 2009).

Functionally, the predominant effect of cholesterol on eNaC is inhibition of channel activity by cholesterol depletion. First, Shlyonsky et al. (2003) showed that functional eNaC channels can be found only in low-density Triton-insoluble fractions (rafts) whereas channels that partition into Triton-soluble fractions appear to be non-functional, as determined by incorporation of reconstituted proteoliposomes into lipid bilayers. Surprisingly, in this study no effect of cholesterol depletion was detected on transepithelial $\mathrm{Na}^{+}$current or single channel eNaC activity. To explain this controversy Shlyonsky et al. (2003) suggested that microdomains surrounding eNaC channels in A6 renal epithelial cells may be resistant to cholesterol depletion. More recently, however, several studies have shown that cholesterol depletion results in a decrease in the basal and/or hormone-stimulated $\mathrm{Na}^{+}$transport (Balut et al., 2006; Hill et al., 2007; West and Blazer-Yost, 2005), and in a decrease in both the open probability (Balut et al., 2006) and the surface expression of eNaC channels (Hill et al., 2007). It is also noteworthy that cholesterol depletion of apical and basal membranes has 
significantly different effects (Balut et al., 2006; West and Blazer-Yost, 2005). Interestingly, Wei et al. (2007) showed that the effect of cholesterol depletion was significantly facilitated by membrane stretch.

In general, loss of channel activity after cholesterol depletion suggests that the scaffold of a lipid raft and interactions with other proteins are required for $\mathrm{eNaC}$ normal function. However, recently it was shown that caveolin-1 is actually a negative regulator of eNaC (Lee et al., 2009), suggesting that it is an interaction with other regulatory molecules that could be responsible for the inhibition of the channels by cholesterol depletion.

\subsection{Ca+ Channels}

\subsubsection{Voltage-Gated $\mathrm{Ca}^{+2}\left(\mathrm{Ca}_{\mathrm{v}}\right)$ Channels}

Voltage-gated $\mathrm{Ca}^{+2}$ channels are also members of the superfamily of ion channels that include voltage-gated $\mathrm{K}^{+}$and $\mathrm{Na}^{+}$channels and they are responsible for calcium influx in response membrane depolarization controlling muscle contraction, secretion, neurotransmission and gene expression in a variety of cell types (Catterall et al., 2005b). The pore forming $\alpha$-subunit of $\mathrm{Ca}_{\mathrm{v}}$ channels is homologous to that of $\mathrm{Na}_{\mathrm{v}}$ channels (Catterall et al., 2005b). The family of $\mathrm{Ca}_{\mathrm{v}}$ channels includes 10 members that belong to one of three subfamilies: the $\mathrm{Ca}_{\mathrm{v}} 1$ subfamily that underlies L-type $\mathrm{Ca}^{+2}$ currents, the $\mathrm{Ca}_{\mathrm{v}} 2$ subfamily that includes $\mathrm{P} / \mathrm{Q}, \mathrm{N}$ and R-type $\mathrm{Ca}^{+2}$ currents and the $\mathrm{Ca}_{\mathrm{v}} 3$ subfamily that underlies T-type $\mathrm{Ca}^{+2}$ currents (Catterall et al., 2005b). Changes in membrane cholesterol were shown to regulate members of all three subfamilies $\mathrm{Ca}_{\mathrm{v}}$ channels: L-type $\mathrm{Ca}^{2+}$ channels (Balijepalli et al., 2006; Bowles et al., 2004; Cox and Tulenko, 1995; Pouvreau et al., 2004), N-type $\mathrm{Ca}^{2+}$ channels (Lundbaek et al., 1996; Toselli et al., 2005), and P/Q-type $\mathrm{Ca}^{2+}$ channels (Taverna et al., 2004). However, specific effects are highly diverse and vary not only between the channel types but also between different cell types and experimental conditions, even for the same types of channels.

\subsubsection{L-Type $\mathrm{Ca}^{2+}$ Channels}

One of the first reports of cholesterol sensitivity of L-type $\mathrm{Ca}^{2+}$ channels demonstrated that Ltype $\mathrm{Ca}^{2+}$ currents are augmented in freshly dispersed myocytes from a rabbit portal vein under dietary hypercholesterolemia (Cox and Tulenko, 1995). Consistent with these observations, (Pouvreau et al., 2004) showed that depleting cellular cholesterol in mice skeletal muscle cells resulted in a significant reduction of L-type $\mathrm{Ca}^{2+}$ channels and $\sim 15 \mathrm{mV}$ positive shift in activation. Kinetics of both activation and inactivation were slowed down. Cholesterol depletion also resulted in disorganization of the T-tubule system, a decrease in the number of caveolae connected to the plasma membrane, and a decrease in cell capacitance which could partially explain the loss of $\mathrm{Ca}^{2+}$ current. However, the decrease in current appeared to be stronger than predicted on the basis of the loss of electrical capacitance suggesting that removal of cholesterol also affects the properties of the channels. Unexpectedly, cholesterol depletion facilitated activation of the channels by the saturating concentrations of Bay K 8644, suggesting that while the basal activity of the channels is inhibited by cholesterol depletion, their sensitivity to stimulation is enhanced. More recently, it was shown that $\mathrm{Ca}_{\mathrm{v}} 1.2$ channels colocalize with caveolin-3 in cardiac myocytes and that $\mathrm{M} \beta \mathrm{CD}$-induced cholesterol depletion completely abolishes $\beta 2$-adrenergic stimulation of $\mathrm{Ca}_{\mathrm{v}} 1.2$ channels in these cells (Balijepalli et al., 2006; Tsujikawa et al., 2008). It is important to note that this effect is consistent with the loss of $\beta$ adrenergic stimulation of the $\mathrm{Na}_{\mathrm{v}} 1.5$ current by anti-caveolin antibodies that was described earlier (Yarbrough et al., 2002).

In contrast, Jennings et al. (1999) showed that L-type $\mathrm{Ca}^{2+}$ channels in gall bladder cells are strongly inhibited by enriching the cells with cholesterol, using the cholesterol-saturated cyclodextrin complex. A similar effect was also demonstrated in coronary smooth muscle cells 
(Bowles et al., 2004). Consistent with these observations, L-type $\mathrm{Ca}^{2+}$ channels were also shown to be inhibited by hypercholesterolemic serum when the channels were recorded in myocytes isolated from conduit coronary arteries. Suppression of the channels was fully reversed by $\mathrm{M} \beta \mathrm{CD}$-induced cholesterol depletion (Bowles et al., 2004). However, hypercholesterolemia had no effect on L-type $\mathrm{Ca}^{2+}$ channels in myocytes isolated from arterioles of the same pigs. Furthermore, cholesterol enrichment had no effect on L-type $\mathrm{Ca}^{2+}$ channels in neuroblastoma-glioma cells (Toselli et al., 2005).

\subsubsection{N-Type $\mathrm{Ca}^{2+}$ Channels}

$\mathrm{N}$-type $\mathrm{Ca}^{2+}$ channels have also been shown to have different sensitivities to membrane cholesterol in different cell types. An increase in membrane cholesterol was shown to alter the inactivation properties but not to affect the activation of $\mathrm{N}$-types $\mathrm{Ca}^{2+}$ channels in neuroblastoma IMR32 cells (Lundbaek et al., 1996), whereas in neuroblastoma-glioma hybrid cells an increase in membrane cholesterol strongly suppressed $\mathrm{N}$-type $\mathrm{Ca}^{2+}$ channels, without having a significant effect on the inactivation of the current (Toselli et al., 2005). The mechanism underlying cholesterol sensitivity of $\mathrm{N}$-type $\mathrm{Ca}^{2+}$ channels in neuroblastomaglioma hybrid cells seems to be strikingly similar to that of inwardly-rectifying $\mathrm{K}^{+}$channels (Romanenko et al., 2004a). Specifically, an increase in membrane cholesterol had no effect on the unitary conductance of the channels and a small effect on the open probability of the channels. The most prominent effect of cholesterol was an increase in the number of sweeps that had no channel activity, suggesting that the channels are stabilized in the closed state (Toselli et al., 2005). Interestingly, activity of $\mathrm{N}$-type $\mathrm{Ca}^{2+}$ channels was also significantly reduced by transfecting the cells with caveolin-1 (Toselli et al., 2005), suggesting that N-type $\mathrm{Ca}^{2+}$ channels may also be suppressed by the interaction with caveolin. However, Toselli et al. (2005) have also shown that caveolin-induced suppression of the current was not due to the interaction of the channels with the caveolin inhibitory scaffolding domain. Therefore, these workers suggested that since caveolin is a cholesterol-binding protein that facilitates cholesterol transport to the plasma membrane, the negative effect of caveolin on N-type $\mathrm{Ca}^{2+}$ channels can be attributed to an increase in membrane cholesterol. Thus, it is interesting to take into account that cholesterol may affect not only the interactions of the channels with caveolin but also that caveolin may affect the interactions of the channels with cholesterol.

\subsection{Transient Receptor Potential (TRP) Channels}

Transient receptor potential or TRP channels are relatively non-selective ion channels, which are activated and regulated by a wide variety of stimuli. For example, TRP channels respond to temperature, touch, pain, osmolarity, pheromones, and taste (Clapham, 2003). They are ubiquitously expressed in many cell types and tissues. The mammalian TRP channels superfamily consists of six related protein families but with sequence identity as low as $20 \%$ (Clapham, 203). Among these, the three major families are the vanilloid (TRPV), the canonical (TRPC) and the melastatin (TRPM) TRP channels (Clapham, 203; Pedersen et al., 2005). Members of each of these three families have been shown to be sensitive to cholesterol and/ or localize in cholesterol-rich lipid rafts.

\subsubsection{TRPV Channels}

Among the TRPV channels that include five members (TRPV1,2,4-6), the activity of TRPV1 has been shown to be sensitive to membrane cholesterol content, suggesting the raft association is pivotal for the physiological role of the channel (Liu et al., 2006). Specifically, it has been demonstrated that there is a close link between cholesterol levels, the amount of TRPV1 in the plasma membrane and TRPV1-mediated responses in primary sensory neurons. Cholesterol depletion following treatment with $\mathrm{M} \beta \mathrm{CD}$ reduced significantly whole cell inward currents thus reducing the level of immunoreactivity of TRPV1 on the surface of the dorsal root ganglion 
neurons. Thus, it was suggested that TRPV1 is localized in cholesterol-rich microdomains, whose integrity determines the function and membrane expression of TRPV1 (Liu et al., 2006).

\subsubsection{TRPC Channels}

Functional expression of TRPC channels (seven members: TRPC1-7) has been shown to enhance store-mediated $\mathrm{Ca}^{2+}$ entry in a variety of mammalian cells (Brownlow et al., 2004; Grimaldi et al., 1999; Hartwig, 1992). Several TRPC channels have been shown to segregate into lipid rafts (Brownlow, 2005), and there is growing evidence that some members of the TRPC channels family assemble in cholesterol-rich caveolae domains in order to participate in $\mathrm{Ca}^{2+}$ influx pathways. Specifically, TRPC1, TRPC4 and TRPC5 were found to be predominantly associated with detergent-resistant, insoluble platelet fractions, from which they were partially released following cholesterol depletion following M $\beta C D$ treatment (Brownlow, 2005). Furthermore, it has been shown that when cholesterol depletion of the plasma membrane disrupts lipid raft domains, it reduces both thapsigargin-and thrombin-evoked $\mathrm{Ca}^{2+}$ entry in human platelets (Brownlow et al., 2004). Together, these results suggest that TRPC1, TRPC4, and TRPC5 are associated with lipid raft domains in human platelets (Brownlow, 2005).

A similar observation was reported for the distribution of TRPC1 in sympathetic neurons, in which TRPC1 was found to be localized in caveolae where it is associated with signalling proteins (Beech, 2005; Delmas, 2004). These data are also consistent with the partition of TRPC1 into detergent insoluble membrane fractions that was observed in several additional cell types, including HSG cells, THP-1 monocytic cells, neutrophils and skeletal myoblasts (Berthier et al., 2004; Brazer et al., 2003; Formigli et al., 2009; Kindzelskii et al., 2004; Lockwich et al., 2000). Further investigation elucidated the molecular determinants of the localization of TRPC1 in caveolae. It was determined that TRPC1 segregates into lipid rafts by binding to the raft-associated protein caveolin-1 (Lockwich et al., 2000), whose scaffolding domain is necessary for anchoring the channel to caveolae and for its regulation (Brazer et al., 2003; Kwiatek et al., 2006). Specifically, the N-terminus of TRPC1 contains a cav-1 binding motif and its $\mathrm{C}$-terminus contains a caveolin scaffolding consensus binding domain that allows for its physical and functional interaction with caveolin-1 in the caveolae of human pulmonary artery endothelial cells (Kwiatek et al., 2006; Remillard and Yuan, 2006). The critical role that lipid raft domains play in the activation of TRPC1 channels has also been confirmed using caveolin knock-out mice (Murata et al., 2007).

Furthermore, excess of cholesterol (Kannan et al., 2007) or 7-ketocholesterol (Berthier et al., 2004) has been shown to induce TRPC1 redistribution to raft fractions. Colocalization of TRPC1 with caveolin-1 was reduced following cholesterol depletion by $\mathrm{M} \beta \mathrm{CD}$, and similarly to the case in human platelets (Brownlow, 2005), $\mathrm{Ca}^{2+}$ inflow was reduced in $\mathrm{M} \beta \mathrm{CD}$-treated caudal arteries (Bergdahl et al., 2003). Since 7-ketocholesterol is a major component of oxLDL, the effect of oxLDL on TRPC1 function was also investigated (Ingueneau et al., 2008). It was found that oxLDL-induced TRPC1 translocation depended on actin cytoskeleton and was associated with a significant increase in the concentration of 7-ketocholesterol (a major oxysterol in oxLDL) into caveolar membranes. Since the cells were treated mildly with oxLDL, in these experiments, the caveolar content of cholesterol was unchanged (Ingueneau et al., 2008).

A different point of view on the relevance of lipid rafts to the function of TRPC1 was obtained by investigating the relationship between TRPC1 and STIM1, an ER $\mathrm{Ca}^{2+}$ protein that was suggested to be involved in coupling of $\mathrm{ER} \mathrm{Ca}^{2+}$ entry channels (Lewis, 2007; Liou et al., 2005; Roos et al., 2005). In this context it has been shown for HSG and HEK cells that TRPC1 and STIM1 associated with each other within the lipid raft domains, and this association was

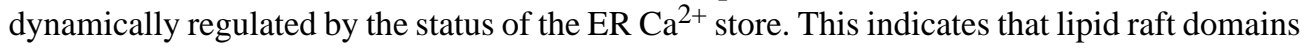


facilitate the store-dependent interaction of STIM1 with TRPC1 (Pani et al., 2008) and suggests that TRPC1 functions as a component of store-operated channels only when linked to STIM1 in lipid rafts (Beech et al., 2009).

For TRPC3, the data is inconclusive. It was first reported that in HEK cells, TRPC3 was assembled in a multimolecular complex with key $\mathrm{Ca}^{2+}$ signalling proteins. It was thus suggested that caveolar localization of TRPC 3 determines the activation and regulation of TRPC3 (Lockwich et al., 2001). Later it was reported that TRPC3 was evenly distributed between insoluble and soluble platelet fractions, and that its distribution was unaffected by M $\beta C D$ (Beech, 2005). It was thus suggested that TRPC3 did not associate with lipid raft domains in human platelets (Beech, 2005). A year later it was reported that in HEK cells its activity was sensitive to membrane cholesterol content, and cholesterol-loading of cells had a positive effect on signals related to TRPC3 (Graziani et al., 2006). Furthermore, increased surface expression of TRPC 3 was identified as a prominent event associated with cholesterolinduced TRPC 3 activation (Graziani et al., 2006). Further experiments would be required to elucidate the conditions that determine the distribution of TRPC 3 in lipid rafts.

As noted above, similarly to TRPC1, TRPC4 has also been associated with lipid raft domains in human platelets (Brownlow, 2005). This observation is in agreement with data obtained from interstitial cells of Cajal, which are considered to be the pacemaker cells in gastrointestinal tracts. Specifically, TRPC4 was found to be located mostly in caveolae and colocalized with caveolin-1 (Torihashi et al., 2002).

TRPC6, similarly to TRPC3, showed a similar distribution between insoluble and soluble platelet fractions, but its distribution was unaffected by $\mathrm{M} \beta C D$, suggesting that it is not associated with lipid raft domains in human platelets, TRPC6 (Brownlow, 2005). A similar observation was reported for the distribution of TRPC6 in sympathetic neurons, where TRPC6 was evenly distributed throughout the plasma membrane (Beech, 2005; Delmas, 2004). On the other hand, it was demonstrated in HEK cells that cholesterol can have an indirect effect on channel function (Huber et al., 2006). Podocin, a cholesterol binding protein was shown to interact and regulate the activity of TRPC6 in a cholesterol-dependent manner. Cholesterol depletion using $\mathrm{M} \beta \mathrm{CD}$ inhibited the effect of podocin on the channel (Beech et al., 2009; Huber et al., 2006).

\subsection{TRPM Channels}

Amongst the TRPM channels (eight members: TRPM1-8), two channels have been investigated in this context, TRPM7 and TRPM8. TRPM7 accumulates at the cell membrane in response to bradykinin-stimulation (Langeslag et al., 2007). Cell fractionation by sucrose gradient and differential centrifugation demonstrated that in bradykinin-stimulated cells, TRPM7 localized in fractions corresponding to caveolae whereas in basal conditions, TRPM7 was almost undetectable in cholesterol-rich fractions (Yogi et al., 2009). This suggests that TRPM7/caveolae/lipid raft association may facilitate TRPM7 scaffolding to cell membrane receptors. In sensory neurons, TRPM8 was found to be localized in cholesterol-rich lipid rafts both in-vivo and in heterologous expression systems (Morenilla-Palao et al., 2009). It has been shown that lipid-raft segregation of TRPM8 is favored by glycosylation at the Asn934, and mutating this asparagine to a glutamine that prevents glycosylation at this position, reduces the amount of TRPM 8 channels that are associated with lipid-rafts by approximately $50 \%$, without affecting the total amount of expressed protein or protein cell surface trafficking (MorenillaPalao et al., 2009). This suggests that lipid raft association modulates TRPM8 activity.

Specifically, both menthol- and cold- mediated responses are enhanced when the channel is located outside the lipid raft, and lipid raft disruption shifts the threshold for TRPM8 activation to warmer temperatures (Morenilla-Palao et al., 2009). 


\section{$19.10 \mathrm{Cl}^{-}$Channels}

In general, $\mathrm{Cl}^{-}$channels can be loosely classified based on their gating mode to voltage-gated, ligand-gated, $\mathrm{Ca}^{2+}$-activated channel superfamilies and channels regulated by cell volume (VRAC) and by cyclic nucleotide-dependent kinases (Cystic Fibrosis Transmembrane Conductance Regulator, CFTR) (Jentsch et al., 2002; Nilius and Droogmans, 2003; Suzuki et al., 2006). Multiple channels from all the classes have been found to be regulated by cholesterol, except $\mathrm{Ca}^{2+}$-activated $\mathrm{Cl}^{-}$channels - currently there is no direct evidence for cholesterol sensitivity of these channels.

\subsubsection{Voltage-Gated $\mathrm{Cl}^{-}$Channels}

The families of $\mathrm{ClC}$ channels and the mitochondrial porins (voltage-dependent anion channels, VDAC) can be assigned to this group of channels. There are nine known mammalian isoforms of $\mathrm{ClC}$ channels with different tissue distribution and function (Jentsch, 2008). Among these channels only ClC-2 has been demonstrated to be regulated by cholesterol. Though $\mathrm{ClC}-2$ is broadly expressed, its biological significance is still vague (Jentsch, 2008; Thiemann et al., 1992). When expressed in HEK293 cells, CLC-2 channel protein was found to be concentrated in cholesterol-rich microdomains and this association was disrupted by cholesterol depletion. Membrane cholesterol was shown to regulate the activation kinetics of the channel resulting in a shift in the activation curve, as well as to regulate channel trafficking (Hinzpeter et al., 2007). Identification of $\mathrm{ClC}-2$ and $\mathrm{ClC}-3$ channels as a part of the neuronal fusion pore, a process that requires cholesterol, suggests that cholesterol-sensitivity of these channels may affect pore formation (Cho et al., 2007; Jena, 2008). However, a specific functional link between the channels and cholesterol has not been established yet.

The voltage-dependent anion channel (VDAC) in the mitochondrial outer membrane is a major metabolite pathway across the membrane and plays an essential role in intracellular signalling and apoptosis (Rostovtseva and Bezrukov, 2008; Shoshan-Barmatz et al., 2006). Sterols such as cholesterol and ergosterol have been found to form a complex with purified VDAC protein (De Pinto et al., 1989; Freitag et al., 1982). Further, Popp et al. (1995) demonstrated that cholesterol is necessary for functional reconstitution of VDAC and that voltage dependence of the channel depends on the sterol used for the reconstitution. Several studies suggested that mitochondrial proteins, including VDAC, are present in lipid rafts of mitochondrial membranes (Foster and Chan, 2007). However, Zheng et al. (2009) showed that raft localization of none of the mitochondrial proteins was affected by cholesterol depletion, which suggested that previous findings could be an artifact of the raft preparation methods. Nevertheless, similarly to the plasma membrane, distinct glycosphingolipid enriched microdomains are present in the mitochondrial membrane with VDAC preferentially partitioning into these domains. Moreover, activation of death receptors recruited other components of the permeability transition pore, including pro-apoptotic Bax and tBid, to the same microdomains (Garofalo et al., 2005). Electrophysiological studies have demonstrated that VDAC voltage gating can be regulated by tBid in planar membranes (Rostovtseva et al., 2004; Rostovtseva and Bezrukov, 2008). Finally, cholesterol depletion abrogated the death-inducing pore formation and prevented mitochondrial depolarization (Christenson et al., 2008; Garofalo et al., 2005; Lucken-Ardjomande et al., 2008; Martinez-Abundis et al., 2007).

\subsubsection{CFTR}

CFTR is a $\mathrm{Cl}^{-}$channel regulated by cyclic AMP and GMP and is critically involved in water and salt transport in multiple types of epithelial tissues. Genetic defects in the CFTR gene and the consequent malfunction of the channel lead to cystic fibrosis (CF), a fatal disease that affects the lungs, liver, pancreas, and the gastrointestinal tract (Rowntree and Harris, 2003). In addition, CFTR has been found to regulate various proteins, including transporters such as 
eNaC and $\mathrm{K}^{+}$and $\mathrm{Cl}^{-}$channels (Berdiev et al., 2009; Schwiebert et al., 1995; Yoo et al., 2004).

Cholesterol-dependent regulation of CFTR currents have been described for its most common mutant deltaF508, which is defective in folding, membrane targeting, and stability but retains some of the channel's functionality (Cheng et al., 1990). Cholesterol depletion partially rescued the CFTR-mediated anion efflux in 3T3 fibroblasts expressing the mutant channel, which was attributed to enhanced plasma membrane targeting and retention of the channel (Lim et al., 2007). Similarly, reduced temperature, chemical chaperons or proteasome inhibitors were previously suggested to partially reverse the folding defect of the deltaF508 mutant (Jiang et al., 1998; Kopito, 1999). In multiple native and expressed cell systems, the CFTR protein was found to be associated with lipid rafts (Dudez et al., 2008; Grassme et al., 2003; Kowalski and Pier, 2004; Vij et al., 2009), but changes in membrane cholesterol were shown to have no effect on the activity of the channels (Lam et al., 2004; Singh et al., 2000; Wang et al., 2008). On the other hand, it has been shown that cholesterol may modulate CFTR-dependent regulation of various pathways, such as NFאB mediated IL-8 signalling (Vij et al., 2009), gap junction modulation by TNF-a (Dudez et al., 2008), and apoptosis induced by P. aeruginosa infection (Kowalski and Pier, 2004). In these studies disruption of lipid rafts and dissociation of CFTR from signalling complexes has been proposed as the mechanism of the cholesterol-dependent modulation.

\subsection{Volume-Regulated Anion Channel (VRAC)}

Maintenance of cell volume and osmotic homeostasis is the most prominent function of VRAC channels (coupled with swelling-activated conductive $\mathrm{K}^{+}$transporters) in most animal cells (Hoffmann et al., 2009). Additionally, VRAC channels are also involved in cell cycle progression, proliferation, and apoptosis (Nilius and Droogmans, 2001; Stutzin and Hoffmann, 2006). The properties and regulatory pathways of VRAC have been extensively studied; however the molecular identity of the channel is still unknown. Moreover, it is also debated as to VRAC, which can conduct amino acids such as taurine, is the main conducting pathway for swelling-induced release of organic osmolytes (Shennan, 2008).

Our studies have shown that membrane cholesterol has a negative effect on VRAC, as is manifested by an increase in amplitude and/or rate of swelling-induced current development in cholesterol-depleted cells and by the suppression of the current by cholesterol enrichment (Byfield et al., 2006; Levitan et al., 2000; Romanenko et al., 2004b). Similar observations were also reported by other investigators (Klausen et al., 2006). Likewise, swelling-induced efflux of anionic osmolytes in several cell types was enhanced by cholesterol depletion and suppressed by cholesterol enrichment (Cheema and Fisher, 2008; Lambert, 2004; Lim et al., 2006; Ortenblad et al., 2003). In terms of the mechanism, cholesterol-dependent regulation of VRAC and swelling-induced osmolyte release was ascribed to changes in the physical properties of the membrane rather than to specific sterol-protein interactions, because substitution of endogenous cholesterol by its analogues, such as epicholesterol, produced no effect on VRAC (Fig. 19.6) (Byfield et al., 2006; Cheema and Fisher, 2008; Romanenko et al., 2004b). Remarkably, cholesterol depletion upregulated VRAC activated by a supra-maximal concentration of GTP $\gamma$ S (Rho GTPase agonist) and, on the contrary, cholesterol sensitivity was lost when VRAC was activated by "strong" hypotonic shock. Moreover, at high cholesterol levels only swelling-activated VRAC was cholesterol-sensitive but not GTP $\gamma \mathrm{S}$-activated VRAC. It was therefore suggested that cholesterol may affect VRAC development by more than one mechanism (Levitan et al., 2000; Romanenko et al., 2004b).

Association with lipid rafts has also been hypothesized as a mechanism for cholesterol sensitivity of VRAC. Indeed, several studies demonstrate correlation of caveolin-1 expression 
with VRAC activation and swelling-induced taurine release. Paradoxically, ablation of caveolin-1 expression, which destabilized lipid rafts as did cholesterol depletion, inhibited VRAC (Trouet et al., 2001; Trouet et al., 1999; Ullrich et al., 2006). Caveolae/lipid rafts were shown to serve as scaffolds for multiple proteins that are involved in VRAC regulation, including Rho GTPases, as well as anchoring sites for actin filaments (Allen et al., 2007; Levitan and Gooch, 2007). Specifically, in ELA cells Klausen et al. (2006) showed that F-actin and Rho-Rho kinase modulate VRAC magnitude and activation rate, respectively, and that cholesterol depletion potentiates VRAC at least in part by preventing the hypotonicity-induced decrease in Rho activity and eliciting actin polymerization. A complex interplay of raftdependent factors may underlie the controversial effects of cholesterol and caveolin.

\subsection{Mechanosensitive Channels}

Finally, we will discuss cholesterol sensitivity of mechanically sensitive ion channels that are expressed ubiquitously in a variety of tissues and are activated by membrane stretch (Hamill and McBride, 1996; Sachs and Morris, 1998). It has been suggested that lipid bilayer and submembranous cytoskeleton structures are involved in the control of mechanosensitive channels (Hamill and Martinac, 2001). Very little, however, is known about cholesterol sensitivity of endogenous stretch-activated channels in eukaryotic cells.

Within human Leukemia K562 cells cholesterol-depletion with M $\beta C D$ resulted in suppression of the activity of mechanosensitive channels (Morachevskaya et al., 2007). It was shown that while cholesterol depletion did not affect the unitary conductance, the open probability of the channel was significantly decreased. At the same time, F-actin revealed reorganization of cortical cytoskeleton in these leukemia cells after cholesterol depletion. The integrity of Factin is critical for the stiffening of cellular membranes, which has been shown to increase following cholesterol depletion (Byfield et al., 2004). It was thus suggested that F-actin rearrangement underlies changes in the mechanical properties of the cell surface, presumably induced by lipid raft destruction and thus mediates the modulation of mechanosensitive channel activity due to cholesterol depletion (Morachevskaya et al., 2007). In B-lymphocytes, the principal cellular mediators of specific humoral immune response to infection, mechanical stimulation reversibly activates $\mathrm{LK}_{\mathrm{bg}}$ large conductance background-type $\mathrm{K}^{+}$channels (Nam et al., 2007). It has been suggested that mechanosensitive activation of $\mathrm{LK}_{\mathrm{bg}}$ channels is mediated by PLC-dependent hydrolysis of $\mathrm{PIP}_{2}$. Inhibition of $\mathrm{LK}_{\mathrm{bg}}$ channels by $\mathrm{PIP}_{2}$ was found to be partially reversible. Interestingly, cholesterol depletion achieved by application of $\mathrm{M} \beta \mathrm{CD}$, induced full recovery of $\mathrm{LK}_{\mathrm{bg}}$ activity from inhibition by $\mathrm{PIP}_{2}$, and facilitated its stretch activation (Nam et al., 2007).

\subsection{Concluding Remarks and Future Directions}

The main conclusion of this chapter is that cholesterol clearly is a major regulator of ion channel function. As described in detail above, changes in the level of membrane cholesterol regulate the activity and the biophysical properties of numerous ion channels including members of all major classes of channels. It is also clear from the variability of cholesterol effects on different types of ion channels that more than one mechanism may underlie the sensitivity of the channels to cholesterol.

However, much less is known about the specific mechanisms responsible for these effects. Furthermore, even the most basic question of whether cholesterol regulates the channels directly or by altering other signalling pathways, which in turn regulate channel activity, is still open in most cases. The most straightforward approach to discriminate between these possibilities is to test whether cholesterol regulates the channels in non-cellular environments, such as lipid planar bilayers or liposomes. Indeed, several types of channels, such as largeconductance $\mathrm{Ca}^{+2}$-sensitive $\mathrm{K}^{+}(\mathrm{BK})$ channels, were shown to be suppressed by cholesterol 
when incorporated into the bilayers, but for the majority of the channels this information is still missing. Moreover, to completely exclude the possibility that cholesterol effects ion channels are indirect, it would be necessary to test these effects on purified channels rather than on channels isolated together with the complex environment of the surrounding plasma membrane. The major constraint in performing these experiments is the difficulty of purifying mammalian channels and it remains as a challenge for future studies.

Another basic question is whether cholesterol regulates ion channels by altering the physical properties of the lipid bilayer or by specific sterol-protein interactions. In several studies, this question was addressed by testing whether there is a correlation between the effect of cholesterol on membrane fluidity and on channel function. Clearly, however, it is not enough to discriminate between these possibilities, because since it is well known that cholesterol alters membrane fluidity, other cholesterol effects will correlate with the changes in fluidity regardless of whether fluidity is indeed responsible for these effects. A better approach is to compare the effects of multiple sterols that are similar to cholesterol in terms of their effects on membrane fluidity and other physical properties of the membrane. Using this approach, we showed that Kir2 channels are sensitive to the chiral nature of cholesterol, whereas VRAC channels are not, suggesting that Kir2 channels are regulated by specific sterol-protein interactions whereas VRAC channels are regulated by changes in the physical properties of the membrane. Applying this approach to purified channels will unambiguously determine whether cholesterol specifically interacts with ion channels.

Finally, the fundamental question remains as to what are the structural determinants of the sensitivity of ion channels to cholesterol. Our recent studies provided the first clues about the structural requirements of cholesterol sensitivity of an ion channel for Kir2 channels, but no information exists to-date on other ion channels. It is possible, however, that since Kir channels are homologous with the basic sub-units of voltage-gated $\mathrm{K}^{+}, \mathrm{Na}^{+}$and $\mathrm{Ca}^{+2}$ channels, with the two-transmembrane helices of Kir corresponding to the fifth and sixth transmembrane helices of the voltage-gated channels, identifying the structural basis for cholesterol sensitivity of Kir channels should provide the clues into how cholesterol interact with other channels.

\section{Acknowledgments}

We thank Drs. Francisco Barrantes, Olaf Andersen and Michael Tamkun for allowing us to include illustrations from their work. I also thank Dr. Barrantes and Dr. Andersen for many discussions of these topics that we had over recent years. This work was supported by NIH grants HL073965 and HL083298 for IL

\section{References}

Abi-Char, Jl; Maguy, A.; Coulombe, A.; Balse, E.; Ratajczak, P.; Samuel, J-L.; Nattel, S.; Hatem, SpN. Membrane cholesterol modulates Kv1.5 potassium channel distribution and function in rat cardiomyocytes. The Journal of Physiology 2007;582:1205. [PubMed: 17525113]

Absi M, Burnham MP, Weston AH, Harno E, Rogers M, Edwards G. Effects of methyl beta-cyclodextrin on EDHF responses in pig and rat arteries; association between $\mathrm{SK}(\mathrm{Ca})$ channels and caveolin-rich domains. Br J Pharmacol. 2007

Allen JA, Halverson-Tamboli RA, Rasenick MM. Lipid raft microdomains and neurotransmitter signalling. Nat Rev Neurosci 2007;8:128-140. [PubMed: 17195035]

Babiychuk EB, Smith RD, Burdyga T, Babiychuk VS, Wray S, Draeger A. Membrane cholesterol regulates smooth muscle phasic contraction. J Membr Biol 2004;198:95-101. [PubMed: 15138749]

Balijepalli RC, Foell JD, Hall DD, Hell JW, Kamp TJ. Localization of cardiac L-type Ca2+ channels to a caveolar macromolecular signalling complex is required for beta2-adrenergic regulation. PNAS 2006;103:7500-7505. [PubMed: 16648270]

Balijepalli RC, Kamp TJ. Caveolae, ion channels and cardiac arrhythmias. Progress in Biophysics and Molecular Biology 2008;98:149. [PubMed: 19351512] 
Balut C, Steels P, Radu M, Ameloot M, Driessche WV, Jans D. Membrane cholesterol extraction decreases Na+ transport in A6 renal epithelia. Am J Physiol Cell Physiol 2006;290:C87-C94. [PubMed: 16107507]

Barrantes FJ. Structural basis for lipid modulatioon of nicotinic acetylcholine receptor function. Brain Research Reviews 2004;47:71-95. [PubMed: 15572164]

Beech DJ. TRPC1: store-operated channel and more. Pflugers Arch 2005;451:53-60. [PubMed: 15965706]

Beech DJ, Bahnasi YM, Dedman AM, Al-Shawaf E. TRPC channel lipid specificity and mechanisms of lipid regulation. Cell Calcium 2009;45:583-588. [PubMed: 19324410]

Begenisich T, Nakamoto T, Ovitt CE, Nehrke K, Brugnara C, Alper SL, Melvin JE. Physiological roles of the intermediate conductance, Ca2+-activated potassium channel Kcnn4. J Biol Chem 2004;279:47681-47687. [PubMed: 15347667]

Berdiev BK, Qadri YJ, Benos DJ. Assessment of the CFTR and ENaC association. Mol Biosyst 2009;5:123-127. [PubMed: 19156256]

Bergdahl A, Gomez MF, Dreja K, Xu SZ, Adner M, Beech DJ, Broman J, Hellstrand P, Swärd K. Cholesterol depletion impairs vascular reactivity to endothelin- 1 by reducing store-operated $\mathrm{Ca}^{2+}$ entry dependent on TRPC1. Circ. Res 2003;93:839-847. [PubMed: 14551243]

Berthier A, Lemaire-Ewing S, Prunet C, Monier S, Athias A, Bessède G, Pais de Barros JP, Laubriet A, Gambert P, Lizard G, Néel D. Involvement of a calcium-dependent dephosphorylation of BAD associated with the localization of Trpc-1 within lipid rafts in 7-ketocholesterol-induced THP-1 cell apoptosis. Cell Death Differ 2004;11:897-905. [PubMed: 15105836]

Bhattacharjee A, Kaczmarek LK. For K+ channels, Na+ is the new Ca2+ Trends Neurosci 2005;28:422428. [PubMed: 15979166]

Bichet D, Haass FA, Jan LY. Merging functional studies with structures of inward-rectifier K(+) channels. Nat Rev Neurosci 2003;4:957-967. [PubMed: 14618155]

Bock J, Szabo I, Gamper N, Adams C, Gulbins E. Ceramide inhibits the potassium channel Kv1.3 by the formation of membrane platforms. Biochemical and Biophysical Research Communications 2003;305:890. [PubMed: 12767914]

Bolotina V, Omelyanenko V, Heyes B, Ryan U, Bregestovski P. Variations of membrane cholesterol alter the kinetics of $\mathrm{Ca} 2+$-dependent $\mathrm{K}+$ channels and membrane fluidity in vascular smooth muscle cells. Pflugers Archives 1989;415:262-268. [PubMed: 2622758]

Bond CT, Maylie J, Adelman JP. Small-conductance calcium-activated potassium channels. Ann N Y Acad Sci 1999;868:370-378. [PubMed: 10414306]

Bond CT, Maylie J, Adelman JP. SK channels in excitability, pacemaking and synaptic integration. Curr Opin Neurobiol 2005;15:305-311. [PubMed: 15922588]

Bowles DK, Heaps CL, Turk JR, Maddali KK, Price EM. Hypercholesterolemia inhibits L-type calcium current in coronary macro-, not microcirculation. J. Appl. Physiol 2004;96:2240-2248. [PubMed: 14752123]

Brainard AM, Miller AJ, Martens JR, England SK. Maxi-K channels localize to caveolae in human myometrium: a role for an actin-channel-caveolin complex in the regulation of myometrial smooth muscle $\mathrm{K}^{+}$current. Am. J. Physiol. Cell Physiol 2005;289:C49-C57. [PubMed: 15703204]

Bravo-Zehnder M, Orio P, Norambuena A, Wallner M, Meera P, Toro L, Latorre R, Gonzalez A. Apical sorting of a voltage- and $\mathrm{Ca}^{2+}$-activated $\mathrm{K}^{+}$channel alpha -subunit in Madin-Darby canine kidney cells is independent of N-glycosylation. Proc. Natl. Acad. Sci. U.S.A 2000;97:13114-13119. [PubMed: 11069304]

Brazer SC, Singh BB, Liu X, Swaim W, Ambudkar IS. Caveolin-1 contributes to assembly of storeoperated $\mathrm{Ca}^{2+}$ influx channels by regulating plasma membrane localization of TRPC1. J. Biol. Chem 2003;278:27208-27215. [PubMed: 12732636]

Brownlow SL, Harper AG, Harper MT, Sage SO. A role for hTRPC1 and lipid raft domains in storemediated calcium entry in human platelets. Cell Calcium 2004;35:107-113. [PubMed: 14706284]

Brownlow SL, Sage SO. Transient receptor potential protein subunit assembly and membrane distribution in human platelets. Thromb. Haemost 2005;94:839-845. [PubMed: 16270640]

Byfield FJ, Aranda-Espinoza H, Romanenko VG, Rothblat GH, Levitan I. Cholesterol depletion increases membrane stiffness of aortic endothelial cells. Biophys. J 2004;87:3336-3343. [PubMed: 15347591] 
Byfield FJ, Hoffman BD, Romanenko VG, Fang Y, Crocker JC, Levitan I. Evidence for the role of cell stiffness in modulation of volume-regulated anion channels. Acta Physiol 2006;187:285-294.

Catterall WA, Goldin AL, Waxman SG. International Union of Pharmacology. XLVII. Nomenclature and Structure-Function Relationships of Voltage-Gated Sodium Channels. Pharmacol. Rev 2005a; 57:397-409. [PubMed: 16382098]

Catterall WA, Perez-Reyes E, Snutch TP, Striessnig J. International Union of Pharmacology. XLVIII. Nomenclature and Structure-Function Relationships of Voltage-Gated Calcium Channels. Pharmacol. Rev 2005b;57:411-425. [PubMed: 16382099]

Chang HM, Reitstetter R, Mason RP, Gruener R. Attenuation of channel kinetics and conductance by cholesterol: an interpretation using structural stress as a unifying concept. J. Membrane Biol 1995;143:51-63. [PubMed: 7714888]

Cheema TA, Fisher SK. Cholesterol regulates volume-sensitive osmolyte efflux from human SH-SY5Y neuroblastoma cells following receptor activation. J. Pharmacol. Exp. Ther 2008;324:648-657. [PubMed: 17991810]

Cheng SH, Gregory RJ, Marshall J, Paul S, Souza DW, White GA, O'Riordan CR, Smith AE. Defective intracellular transport and processing of CFTR is the molecular basis of most cystic fibrosis. Cell 1990;63:827-834. [PubMed: 1699669]

Cho WJ, Jeremic A, Jin H, Ren G, Jena BP. Neuronal fusion pore assembly requires membrane cholesterol. Cell Biol. Int 2007;31:1301-1308. [PubMed: 17703958]

Christenson E, Merlin S, Saito M, Schlesinger P. Cholesterol effects on BAX pore activation. J. Mol. Biol 2008;381:1168-1183. [PubMed: 18590739]

Clapham DE. TRP channels as cellular sensors. Nature 2003;426:517-524. [PubMed: 14654832]

Cox RH, Tulenko TN. Altered contractile and ion channel function in rabbit portal vein with dietary atherosclerosis. Am. J. Physiol 1995;268:H2522-H2530. [PubMed: 7541962]

Criado M, Eibl H, Barrantes FJ. Effects of lipids on acetylcholine receptor. Essential need of cholesterol for maintenance of agonist-induced state transitions in lipid vesicles. Biochemistry 1982;21:36223629. [PubMed: 7115688]

Crowley JJ, Treistman SN, Dopico AM. Cholesterol antagonizes ethanol potentiation of human brain BKCa channels reconstituted into phospholipid bilayers. Mol. Pharmacol 2003;64:365-372. [PubMed: 12869641]

Davies PF. Flow-mediated endothelial mechanotransduction. Physiol. Rev 1995;75:519-560. [PubMed: 7624393]

de la Rosa DA, Canessa CM, Fyfe GK, Zhang P. Structure and Regulation of Amiloride-Sensitive Sodium Channels. Ann. Rev. Physiol 2000;62:573. [PubMed: 10845103]

De Pinto V, Benz R, Caggese C, Palmieri F. Characterization of the mitochondrial porin from Drosophila melanogaster. Biochim. Biophys. Acta 1989;987:1-7. [PubMed: 2480813]

Delling M, Wischmeyer E, Dityatev A, Sytnyk V, Veh RW, Karschin A, Schachner M. The Neural Cell Adhesion Molecule Regulates Cell-Surface Delivery of G-Protein-Activated Inwardly Rectifying Potassium Channels Via Lipid Rafts. J. Neurosci 2002;22:7154-7164. [PubMed: 12177211]

Delmas P. Assembly and gating of TRPC channels in signalling microdomains. Novartis Found. Symp 2004;258:75-89. discussion 89-102, 263-266. [PubMed: 15104177]

Demel RA, Bruckdorfer KR, van Deenen LLM. Structural requrements of sterols for the interaction with lecithin at the air-water interface. Biochem. Biophys. Acta 1972;255:311-320. [PubMed: 5010999]

Du P, Cui GB, Wang YR, Zhang XY, Ma KJ, Wei JG. Down regulated expression of the beta1 subunit of the big-conductance $\mathrm{Ca}^{2+}$ sensitive $\mathrm{K}^{+}$channel in sphincter of Oddi cells from rabbits fed with a high cholesterol diet. Acta Biochim. Biophys. Sin. (Shanghai) 2006;38:893-899. [PubMed: 17151783]

Dudez T, Borot F, Huang S, Kwak BR, Bacchetta M, Ollero M, Stanton BA, Chanson M. CFTR in a lipid raft-TNFR1 complex modulates gap junctional intercellular communication and IL-8 secretion. Biochim. Biophys. Acta 2008;1783:779-788. [PubMed: 18255040]

Edwards G, Weston AH. The Pharmacology of ATP-Sensitive Potassium Channels. Ann. Rev. Pharmacol. Toxicol 1993;33:597-637. [PubMed: 8494353]

Eldstrom J, Van Wagoner DR, Moore ED, Fedida D. Localization of Kv1.5 channels in rat and canine myocyte sarcolemma. FEBS Lett 2006;580:6039. [PubMed: 17054951] 
Epshtein Y, Chopra A, Rosenhouse-Dantsker A, Kowalsky G, DE L, Levitan I. Identification of a Cterminus domain critical for the sensitivity of Kir2.1 channels to cholesterol. Proc. Natl. Acad. Sci. U.S.A 2009;106:8055-8060. [PubMed: 19416905]

Fang Y, Mohler ER, Hsieh E III, Osman H, Hashemi SM, Davies PF, Rothblat GH, Wilensky RL, Levitan I. Hypercholesterolemia suppresses inwardly rectifying $\mathrm{k}^{+}$channels in aortic endothelium in vitro and in vivo. Circ. Res 2006;98:1064-1071. [PubMed: 16556870]

Fang Y, Schram G, Romanenko VG, Shi C, Conti L, Vandenberg CA, Davies PF, Nattel S, Levitan I. Functional expression of Kir2.x in human aortic endothelial cells: the dominant role of Kir2.2. Am. J. Physiol. Cell Physiol 2005;289:C1134-C1144. [PubMed: 15958527]

Feletou M. Calcium-activated potassium channels and endothelial dysfunction: therapeutic options? Br. J. Pharmacol 2009;156:545-562. [PubMed: 19187341]

Formigli L, Sassoli C, Squecco R, Bini F, Martinesi M, Chellini F, Luciani G, Sbrana F, Zecchi-Orlandini S, Francini F, Meacci E. Regulation of transient receptor potential canonical channel 1 (TRPC1) by sphingosine 1-phosphate in $\mathrm{C} 2 \mathrm{C} 12$ myoblasts and its relevance for a role of mechanotransduction in skeletal muscle differentiation. J. Cell Sci 2009;122:1322-1333. [PubMed: 19351713]

Foster LJ, Chan QW. Lipid raft proteomics: more than just detergent-resistant membranes. Subcell Biochem 2007;43:35-47. [PubMed: 17953390]

Freitag H, Genchi G, Benz R, Palmieri F, Neupert W. Isolation of mitochondrial porin from Neurospora crassa. FEBS Lett 1982;145:72-76. [PubMed: 6290266]

Garofalo T, Giammarioli AM, Misasi R, Tinari A, Manganelli V, Gambardella L, Pavan A, Malorni W, Sorice M. Lipid microdomains contribute to apoptosis-associated modifications of mitochondria in T cells. Cell Death Differ 2005;12:1378-1389. [PubMed: 15947792]

Gasque, Labarca; Darszon. Cholesterol-depleting compounds modulate $\mathrm{K}^{+}$-currents in Drosophila Kenyon cells. FEBS Lett 2005;579:5129. [PubMed: 16154131]

Ghanam K, Javellaud J, Ea-Kim L, Oudart N. Effects of treatment with 17beta-estradiol on the hypercholesterolemic rabbit middle cerebral artery. Maturitas 2000;34:249-260. [PubMed: 10717491]

Ghanshani S, Wulff H, Miller MJ, Rohm H, Neben A, Gutman GA, Cahalan MD, Chandy KG. Upregulation of the IKCa1 potassium channel during T-cell activation. Molecular mechanism and functional consequences. J. Biol. Chem 2000;275:37137-37149. [PubMed: 10961988]

Grassme H, Jendrossek V, Riehle A, von Kurthy G, Berger J, Schwarz H, Weller M, Kolesnick R, Gulbins E. Host defense against Pseudomonas aeruginosa requires ceramide-rich membrane rafts. Nat. Med 2003;9:322-330. [PubMed: 12563314]

Graziani A, Rosker C, Kohlwein SD, Zhu MX, Romanin C, Sattler W, Groschner K, Poteser M. Cellular cholesterol controls TRPC3 function: evidence from a novel dominant-negative knockdown strategy. Biochem. J 2006;396:147-155. [PubMed: 16448384]

Grimaldi M, Favit A, Alkon DL. cAMP-induced cytoskeleton rearrangement increases calcium transients through the enhancement of capacitative calcium entry. J. Biol. Chem 1999;274:33557-33564. [PubMed: 10559242]

Gutman GA, Chandy KG, Grissmer S, Lazdunski M, McKinnon D, Pardo LA, Robertson GA, Rudy B, Sanguinetti MC, Stuhmer W, Wang X. International Union of Pharmacology. LIII. Nomenclature and Molecular Relationships of Voltage-Gated Potassium Channels. Pharmacol. Rev 2005;57:473508. [PubMed: 16382104]

Haass FA, Jonikas M, Walter P, Weissman JS, Jan Y-N, Jan LY, Schuldiner M. Identification of yeast proteins necessary for cell-surface function of a potassium channel. Proc. Natl. Acad. Sci. U.S.A 2007;104:18079-18084. [PubMed: 17989219]

Hajdú P, Varga Z, Pieri C, Panyi G, Gáspár RJ. Cholesterol modifies the gating of Kv1.3 in human T lymphocytes. Pflugers Arch 2003;445:674-682. [PubMed: 12632187]

Hamill OP, Martinac B. Molecular basis of mechanotransduction in living cells. Physiol. Rev 2001;81:685-740. [PubMed: 11274342]

Hamill OP, McBride JDW. The pharmacology of mechanogated membrane ion channels. Pharmacol. Rev 1996;48:231-252. [PubMed: 8804105] 
Hanwell D, Ishikawa T, Saleki R, Rotin D. Trafficking and Cell Surface Stability of the Epithelial Na+ Channel Expressed in Epithelial Madin-Darby Canine Kidney Cells. J. Biol. Chem 2002;277:97729779. [PubMed: 11773057]

Hartwig JH. Mechanisms of actin rearrangements mediating platelet activation. J. Cell Biol 1992;118:1421-1442. [PubMed: 1325975]

Heaps CL, Tharp DL, Bowles DK. Hypercholesterolemia abolishes voltage-dependent $\mathrm{K}^{+}$channel contribution to adenosine-mediated relaxation in porcine coronary arterioles. Am. J. Physiol. Heart Circ. Physiol 2005;288:H568-H576. [PubMed: 15458946]

Hibino H, Kurachi Y. Distinct detergent-resistant membrane microdomains (lipid rafts) respectively harvest $\mathrm{K}^{+}$and water transport systems in brain astroglia. Euro. J. Neurosci 2007;26:2539-2555.

Hilgemann DW, Feng S, Nasuhoglu C. The complex and intriguing lives of PIP2 with ion channels and transporters. Sci. STKE 2001;111:RE19. [PubMed: 11734659]

Hill WG, An B, Johnson JP. Endogenously expressed epithelial sodium channel is present in lipid rafts in A6 cells. J. Biol. Chem 2002;277:33541-33544. [PubMed: 12167633]

Hill WG, Butterworth MB, Wang H, Edinger RS, Lebowitz J, Peters KW, Frizzell RA, Johnson JP. The Epithelial Sodium Channel (ENaC) Traffics to Apical Membrane in Lipid Rafts in Mouse Cortical Collecting Duct Cells. J. Biol. Chem 2007;282:37402-37411. [PubMed: 17932048]

Hinzpeter A, Fritsch J, Borot F, Trudel S, Vieu DL, Brouillard F, Baudouin-Legros M, Clain J, Edelman A, Ollero M. Membrane cholesterol content modulates ClC-2 gating and sensitivity to oxidative stress. J. Biol. Chem 2007;282:2423-2432. [PubMed: 17110372]

Hoffmann EK, Lambert IH, Pedersen SF. Physiology of cell volume regulation in vertebrates. Physiol. Rev 2009;89:193-277. [PubMed: 19126758]

Huber TB, Schermer B, Muller RU, Hohne M, Bartram M, Calixto A, Hagmann H, Reinhardt C, Koos F, Kunzelmann K, Shirokova E, Krautwurst D, Harteneck C, Simons M, Pavenstädt H, Kerjaschki D, Thiele C, Walz G, Chalfie M, Benzing T. Podocin and MEC-2 bind cholesterol to regulate the activity of associated ion channels. Proc. Natl. Acad. Sci. U.S.A 2006;103:17079-17086. [PubMed: 17079490]

Ingueneau C, Huynh-Do U, Marcheix B, Athias A, Gambert P, Nègre-Salvayre A, Salvayre R, Vindis C. TRPC1 is regulated by caveolin-1 and is involved in oxidized LDL-induced apoptosis of vascular smooth muscle cells. J. Cell Mol. Med. 2008 (Epub ahead of print).

Jena BP. Porosome: the universal molecular machinery for cell secretion. Mol. Cells 2008;26:517-529. [PubMed: 19011361]

Jennings LJ, Xu Q-W, Firth TA, Nelson MT, Mawe GM. Cholesterol inhibits spontaneous action potentials and calcium currents in guinea pig gallbladder smooth muscle. Am. J. Physiol 1999;277:G1017-G1026. [PubMed: 10564108]

Jentsch TJ. CLC chloride channels and transporters: from genes to protein structure, pathology and physiology. Crit. Rev. Biochem. Mol. Biol 2008;43:3-36. [PubMed: 18307107]

Jentsch TJ, Stein V, Weinreich F, Zdebik AA. Molecular Structure and Physiological Function of Chloride Channels. Physiol. Rev 2002;82:503-568. [PubMed: 11917096]

Jeremy RW, McCarron H. Effect of hypercholesterolemia on Ca2+-dependent K+ channel-mediated vasodilatation in vivo. Am. J. Physiol 2000;279:H1600-H1608.

Jiang C, Fang SL, Xiao YF, O'Connor SP, Nadler SG, Lee DW, Jefferson DM, Kaplan JM, Smith AE, Cheng SH. Partial restoration of cAMP-stimulated CFTR chloride channel activity in DeltaF508 cells by deoxyspergualin. Am. J. Physiol 1998;275:C171-C178. [PubMed: 9688848]

Jiang J, Thorén P, Caligiuri G, Hansson GK, Pernow J. Enhanced phenylephrine-induced rhythmic activity in the atherosclerotic mouse aorta via an increase in opening of $\mathrm{KCa}$ channels: relation to Kv channels and nitric oxide. Br. J. Pharmacol 1999;128:637-646. [PubMed: 10516643]

Kannan KB, Barlos D, Hauser CJ. Free cholesterol alters lipid raft structure and function regulating neutrophil $\mathrm{Ca}^{2+}$ entry and respiratory burst: correlations with calcium channel raft trafficking. J. Immunol 2007;178:5253-5261. [PubMed: 17404309]

Khan RN, Matharoo-Ball B, Arulkumaran S, Ashford ML. Potassium channels in the human myometrium. Exp. Physiol 2001;86:255-264. [PubMed: 11429642] 
Kindzelskii AL, Sitrin RG, Petty HR. Cutting edge: optical microspectrophotometry supports the existence of gel phase lipid rafts at the lamellipodium of neutrophils: apparent role in calcium signalling. J. Immunol 2004;172:4681-4685. [PubMed: 15067042]

King JT, Lovell PV, Rishniw M, Kotlikoff MI, Zeeman ML, McCobb DP. Beta2 and beta4 subunits of BK channels confer differential sensitivity to acute modulation by steroid hormones. J. Neurophysiol 2006;95:2878-2888. [PubMed: 16436475]

Klausen TK, Hougaard C, Hoffmann EK, Pedersen SF. Cholesterol modulates the volume-regulated anion current in Ehrlich-Lettre ascites cells via effects on Rho and F-actin. Am. J. Physiol. Cell. Physiol 2006;291:C757-C771. [PubMed: 16687471]

Kopito RR. Biosynthesis and degradation of CFTR. Physiol. Rev 1999;79:S167-S173. [PubMed: 9922380]

Kowalski MP, Pier GB. Localization of Cystic Fibrosis Transmembrane Conductance Regulator to Lipid Rafts of Epithelial Cells Is Required for Pseudomonas aeruginosa-Induced Cellular Activation. J. Immunol 2004;172:418-425. [PubMed: 14688350]

Kubo Y, Adelman JP, Clapham DE, Jan LY, Karschin A, Kurachi Y, Lazdunski M, Nichols CG, Seino S, Vandenberg CA. International Union of Pharmacology. LIV. Nomenclature and Molecular Relationships of Inwardly Rectifying Potassium Channels. Pharmacol. Rev 2005;57:509-526. [PubMed: 16382105]

Kwiatek AM, Minshall RD, Cool DR, Skidgel RA, Malik AB, Tiruppathi C. Caveolin-1 regulates storeoperated $\mathrm{Ca}^{2+}$ influx by binding of its scaffolding domain to transient receptor potential channel-1 in endothelial cells. Mol. Pharmacol 2006;70:1174-1183. [PubMed: 16822931]

Lam RS, Shaw AR, Duszyk M. Membrane cholesterol content modulates activation of BK channels in colonic epithelia. Biochim. Biophys. Acta 2004;1667:241-248. [PubMed: 15581861]

Lambert IH. Regulation of the cellular content of the organic osmolyte taurine in mammalian cells. Neurochem. Res 2004;29:27-63. [PubMed: 14992263]

Langeslag M, Clark K, Moolenaar WH, van Leeuwen FN, Jalink K. Activation of TRPM7 channels by phospholipase C-coupled receptor agonists. J. Biol. Chem 2007;282:232-239. [PubMed: 17095511]

Langhorst MF, Reuter A, Stuermer CA. Scaffolding microdomains and beyond: the function of reggie/ flotillin proteins. Cell Mol. Life Sci 2005;62:2228-2240. [PubMed: 16091845]

Ledoux J, Werner ME, Brayden JE, Nelson MT. Calcium-activated potassium channels and the regulation of vascular tone. Physiol. (Bethesda) 2006;21:69-78.

Lee I-H, Campbell CR, Song S-H, Day ML, Kumar S, Cook DI, Dinudom A. The Activity of the Epithelial Sodium Channels Is Regulated by Caveolin-1 via a Nedd4-2-dependent Mechanism. J. Biol. Chem 2009;284:12663-12669. [PubMed: 19304660]

Lee T-M, Lin M-S, Chou T-F, Tsai C-H, Chang N-C. Effect of pravastatin on left ventricular mass by activation of myocardial KATP channels in hypercholesterolemic rabbits. Atherosclerosis 2004;176:273. [PubMed: 15380449]

Levitan I, Christian AE, Tulenko TN, Rothblat GH. Membrane cholesterol content modulates activation of volume-regulated anion current (VRAC) in bovine endothelial cells. J. Gen. Physiol 2000;115:405-416. [PubMed: 10736308]

Levitan I, Gooch KJ. Lipid Rafts in Membrane-Cytoskeleton Interactions and Control of Cellular Biomechanics: Actions of oxLDL. Antioxidants \& Redox Signalling 2007;9:1519-1534.

Lewis RS. The molecular choreography of a store-operated calcium channel. Nature 2007;446:284-287. [PubMed: 17361175]

Lim CH, Bijvelds MJ, Nigg A, Schoonderwoerd K, Houtsmuller AB, de Jonge HR, Tilly BC. Cholesterol depletion and genistein as tools to promote F508delCFTR retention at the plasma membrane. Cell Physiol. Biochem 2007;20:473-482. [PubMed: 17762174]

Lim CH, Schoonderwoerd K, Kleijer WJ, de Jonge HR, Tilly BC. Regulation of the cell swelling-activated chloride conductance by cholesterol-rich membrane domains. Acta Physiol 2006;187:295-303.

Lin MW, Wu AZ, Ting WH, Li CL, Cheng KS, Wu SN. Changes in membrane cholesterol of pituitary tumor $(\mathrm{GH} 3)$ cells regulate the activity of large-conductance $\mathrm{Ca}^{2+}$-activated $\mathrm{K}^{+}$channels. Chin. J. Physiol 2006;49:1-13. [PubMed: 16900700] 
Liou J, Kim ML, Heo WD, Jones JT, Myers JW, Ferrell JE Jr, Meyer T. STIM is a $\mathrm{Ca}^{2+}$ sensor essential for $\mathrm{Ca}^{2+}$-store-depletion-triggered $\mathrm{Ca}^{2+}$ influx. Curr Biol 2005;15:1235-1241. [PubMed: 16005298]

Liu M, Huang W, Wu D, Priestley JV. TRPV1, but not P2X, requires cholesterol for its function and membrane expression in rat nociceptors. Eur. J. Neurosci 2006;24:1-6. [PubMed: 16800863]

Lockwich T, Singh BB, Liu X, and Ambudkar IS. Stabilization of cortical actin induces internalization of transient receptor potential 3 (Trp3)-associated caveolar $\mathrm{Ca}^{2+}$ signaling complex and loss of $\mathrm{Ca}^{2+}$ influx without disruption of Trp3-inositol trisphosphate receptor association. J. Biol. Chem 2001;276:42401-42408. [PubMed: 11524429]

Lockwich TP, Liu X, Singh BB, Jadlowiec J, Weiland S, Ambudkar IS. Assembly of Trp1 in a signalling complex associated with caveolin-scaffolding lipid raft domains. J. Biol. Chem 2000;275:1193411942. [PubMed: 10766822]

Logothetis DE, Jin T, Lupyan D, Rosenhouse-Dantsker A. Phosphoinositide-mediated gating of inwardly rectifying $\mathrm{K}^{+}$channels. Pflugers Arch 2007;455:83-95. [PubMed: 17520276]

Logsdon NJ, Kang J, Togo JA, Christian EP, Aiyar J. A novel gene, hKCa4, encodes the calcium-activated potassium channel in human T lymphocytes. J. Biol. Chem 1997;272:32723-32726. [PubMed: 9407042]

Lucken-Ardjomande S, Montessuit S, Martinou JC. Bax activation and stress-induced apoptosis delayed by the accumulation of cholesterol in mitochondrial membranes. Cell Death Differ 2008;15:484493. [PubMed: 18084240]

Lundbaek JA, Andersen OS. Spring constants for channel-induced lipid bilayer deformations estimates using gramicidin channels. Biophys. J 1999;76:889-895. [PubMed: 9929490]

Lundbaek JA, Birn P, Hansen AJ, Andersen OS. Membrane stiffness and channel function. Biochemistry 1996;35:3825-3830. [PubMed: 8620005]

Lundbaek JA, Birn P, Hansen AJ, Sogaard R, Nielsen C, Girshman J, Bruno MJ, Tape SE, Egebjerg J, Greathouse DV, Mattice GL, Koeppe RE, Andersen OS II. Regulation of Sodium Channel Function by Bilayer Elasticity: The Importance of Hydrophobic Coupling. Effects of Micelle-forming Amphiphiles and Cholesterol. J. Gen. Physiol 2004;123:599-621. [PubMed: 15111647]

Maguy A, Hebert TE, Nattel S. Involvement of lipid rafts and caveolae in cardiac ion channel function. Cardiovasc. Res 2006;69:798. [PubMed: 16405931]

Marsh D, Barrantes FJ. Immobilized lipid in acetylcholine receptor-rich membranes from Torpedo marmorata. Proc. Natl. Acad. Sci. U.S.A 1978;75:4329-4333. [PubMed: 212745]

Martens JR, Navarro-Polanco R, Coppock EA, Nishiyama A, Parshley L, Grobaski TD, Tamkun MM. Differential Targeting of Shaker-like Potassium Channels to Lipid Rafts. J. Biol. Chem 2000;275:7443-7446. [PubMed: 10713042]

Martens JR, O'Connell K, Tamkun M. Targeting of ion channels to membrane microdomains: localization of KV channels to lipid rafts. Trends Pharmacol. Sci 2004;25:16-21. [PubMed: 14723974]

Martens JR, Sakamoto N, Sullivan SA, Grobaski TD, Tamkun MM. Isoform-specific Localization of Voltage-gated K+ Channels to Distinct Lipid Raft Populations. Targeting of Kv1.5 to caveolae. J. Biol. Chem 2001;276:8409-8414. [PubMed: 11115511]

Martinez-Abundis E, Garcia N, Correa F, Franco M, Zazueta C. Changes in specific lipids regulate BAXinduced mitochondrial permeability transition. FEBS J 2007;274:6500-6510. [PubMed: 18028444]

Mathew V, Lerman A. Altered effects of potassium channel modulation in the coronary circulation in experimental hypercholesterolemia. Atherosclerosis 2001;154:329-335. [PubMed: 11166765]

McEwen DP, Li Q, Jackson S, Jenkins PM, Martens JR. Caveolin Regulates Kv1.5 Trafficking to Cholesterol-Rich Membrane Microdomains. Mol. Pharmacol 2008;73:678-685. [PubMed: 18045854]

Mohler Iii ER, Fang Y, Gusic Shaffer R, Moore J, Wilensky RL, Parmacek M, Levitan I. Hypercholesterolemia suppresses Kir channels in porcine bone marrow progenitor cells in vivo. Biochem. Biophys. Res. Comm 2007;358:317-324. [PubMed: 17482574]

Morachevskaya E, Sudarikova A, Negulyaev Y. Mechanosensitive channel activity and F-actin organization in cholesterol-depleted human leukaemia cells. Cell Biol. Int 2007;31:374-381. [PubMed: 17317227] 
Morenilla-Palao C, Pertusa M, Meseguer V, Cabedo H, Viana F. Lipid raft segregation modulates TRPM8 channel activity. J. Biol. Chem 2009;284:9215-9224. [PubMed: 19176480]

Murata T, Lin MI, Stan RV, Bauer PM, Yu J, Sessa WC. Genetic evidence supporting caveolae microdomain regulation of calcium entry in endothelial cells. J. Biol. Chem 2007;282:1663116643. [PubMed: 17416589]

Najibi S, Cohen RA. Enhanced role of $\mathrm{K}^{+}$channels in relaxations of hypercholesterolemic rabbit carotid artery to NO. Am. J. Physiol. Heart Circ. Physiol 1995;269:H805-H811.

Najibi S, Cowan CL, Palacino JJ, Cohen RA. Enhanced role of potassium channels in relaxations to acetylcholine in hypercholesterolemic rabbit carotid artery. Am J. Physiol. Heart Circ. Physiol 1994;266:H2061-H2067.

Nam JH, Lee H-S, Nguyen YH, Kang TM, Lee SW, Kim H-Y, Kim SJ, Earm YE, Kim SJ. Mechanosensitive activation of $\mathrm{K}^{+}$channel via phospholipase $\mathrm{C}$-induced depletion of phosphatidylinositol 4,5-bisphosphate in B lymphocytes. J. Physiol 2007;582:977. [PubMed: 17347270]

Nichols C, Lopatin A. Inward rectifier potassium channels. Annu. Rev. Physiol 1997;59

Nichols CG. KATP channels as molecular sensors of cellular metabolism. Nature 2006;440:470. [PubMed: 16554807]

Nilius B, Droogmans G. Ion channels and their functional role in vascular endothelium. Physiol. Rev 2001;81:1415-1459. [PubMed: 11581493]

Nilius B, Droogmans G. Amazing chloride channels: an overview. Acta Physiol. Scand 2003;177:119147. [PubMed: 12558550]

O'Connell KMS, Martens JR, Tamkun MM. Localization of Ion Channels to Lipid Raft Domains within the Cardiovascular System. Trends Cardiovasc. Med 2004;14:37. [PubMed: 15030787]

O'Connell KMS, Tamkun MM. Targeting of voltage-gated potassium channel isoforms to distinct cell surface microdomains. J. Cell Sci 2005;118:2155-2166. [PubMed: 15855232]

O'Connell KMS, Whitesell JD, Tamkun MM. Localization and mobility of the delayed-rectifer K+ channel Kv2.1 in adult cardiomyocytes. Am. J. Physiol. Heart Circ. Physiol 2008;294:H229-H237. [PubMed: 17965280]

Olesen S-P, Clapham DE, Davies PF. Hemodynamic shear stress activates a K+ current in vascular endothelial cells. Nature 1988;331:168-170. [PubMed: 2448637]

Ortenblad N, Young JF, Oksbjerg N, Nielsen JH, Lambert IH. Reactive oxygen species are important mediators of taurine release from skeletal muscle cells. Am J. Physiol. Cell Physiol 2003;284:C1362-C1373. [PubMed: 12519746]

Palygin OA, Pettus JM, Shibata EF. Regulation of caveolar cardiac sodium current by a single Gs \{alpha\} histidine residue. Am. J. Physiol. Heart Circ. Physiol 2008;294:H1693-H1699. [PubMed: 18281377]

Pani B, Ong HL, Liu X, Rauser K, Ambudkar IS, Singh BB. Lipid rafts determine clustering of STIM1 in endoplasmic reticulum-plasma membrane junctions and regulation of store-operated $\mathrm{Ca}^{2+}$ entry (SOCE). J. Biol. Chem 2008;283:17333-17340. [PubMed: 18430726]

Panyi G, Bagdany M, Bodnar A, Vamosi G, Szentesi G, Jenei A, Matyus L, Varga S, Waldmann TA, Gaspar R, Damjanovich S. Colocalization and nonrandom distribution of Kv1.3 potassium channels and CD3 molecules in the plasma membrane of human T lymphocytes. Proc. Natl. Acad. Sci. U.S.A 2003;100:2592-2597. [PubMed: 12604782]

Panyi G, Vamosi G, Bacso Z, Bagdany M, Bodnar A, Varga Z, Gaspar R, Matyus L, Damjanovich S. Kv1.3 potassium channels are localized in the immunological synapse formed between cytotoxic and target cells. Proc. Natl. Acad. Sci. U.S.A 2004;101:1285-1290. [PubMed: 14745040]

Pedersen SF, Owsianik G, Nilius B. TRP channels: an overview. Cell Calcium 2005;38:233-252. [PubMed: 16098585]

Perry MD, Sandle GI. Regulation of colonic apical potassium (BK) channels by cAMP and somatostatin. Am. J. Physiol. Gastrointest. Liver Physiol 2009;297:G159-G167. [PubMed: 19407217]

Pike L, Casey L. Localization and turnover of phosphatidylinositol 4,5-bisphospate in caveolin-enriched membrane domains. J. Biol. Chem 1996;271:26453-26456. [PubMed: 8900109]

Pike LJ. Rafts defined: a report on the Keystone symposium on lipid rafts and cell function. J. Lipid Res 2006;47:1597-1598. [PubMed: 16645198] 
Pongo E, Balla Z, Mubagwa K, Flameng W, Edes I, Szilvassy Z, Ferdinandy P. Deterioration of the protein kinase C-KATP channel pathway in regulation of coronary flow in hypercholesterolaemic rabbits. Euro. J. Pharmacol 2001;418:217.

Pouvreau S, Berthier C, Blaineau S, Amsellem J, Coronado R, Strube C. Membrane cholesterol modulates dihydropyridine receptor function in mice fetal skeletal muscle cells. J. Physiol. (Lond.) 2004;555:365-381. [PubMed: 14724204]

Prince LS, Welsh MJ. Effect of subunit composition and Liddle's syndrome mutations on biosynthesis of ENaC. Am. J. Physiol. Cell Physiol 1999;276:C1346-C1351.

Rehberg B, Urban BW, Duch DS. The membrane lipid cholesterol modulates anesthetic actions on a human brain ion channel. Anesthesiology 1995;82:749-758. [PubMed: 7879943]

Remillard CV, Yuan JX. Transient receptor potential channels and caveolin-1: good friends in tight spaces. Mol. Pharmacol 2006;70:1151-1154. [PubMed: 16873578]

Ren YJ, Xu XH, Zhong CB, Feng N, Wang XL. Hypercholesterolemia alters vascular functions and gene expression of potassium channels in rat aortic smooth muscle cells. Acta Pharmacol. Sin 2001;22:274-278. [PubMed: 11742577]

Romanenko VG, Fang Y, Byfield F, Travis AJ, Vandenberg CA, Rothblat GH, Levitan I. Cholesterol sensitivity and lipid raft targeting of Kir2.1 channels. Biophys. J 2004a;87:3850-3861. [PubMed: 15465867]

Romanenko VG, Nakamoto T, Srivastava A, Begenisich T, Melvin JE. Regulation of membrane potential and fluid secretion by $\mathrm{Ca}^{2+}$-activated $\mathrm{K}^{+}$channels in mouse submandibular glands. J. Physiol 2007;581:801-817. [PubMed: 17379640]

Romanenko VG, Roser KS, Melvin JE, Begenisich T. The role of cell cholesterol and the cytoskeleton in the interaction between IK1 and maxi-K channels. Am J. Physiol. Cell Physiol 2009;296:C878C888. [PubMed: 19176762]

Romanenko VG, Rothblat GH, Levitan I. Modulation of endothelial inward rectifier $\mathrm{K}^{+}$current by optical isomers of cholesterol. Biophys. J 2002;83:3211-3222. [PubMed: 12496090]

Romanenko VG, Rothblat GH, Levitan I. Sensitivity of volume-regulated anion current to cholesterol structural analogues. J. Gen. Physiol 2004b;123:77-88. [PubMed: 14699079]

Roos J, DiGregorio PJ, Yeromin AV, Ohlsen K, Lioudyno M, Zhang S, Safrina O, Kozak JA, Wagner SL, Cahalan MD, Veliçelebi G, Stauderman KA. STIM1, an essential and conserved component of store-operated $\mathrm{Ca}^{2+}$ channel function. J. Cell. Biol 2005;169:435-445. [PubMed: 15866891]

Rostovtseva TK, Antonsson B, Suzuki M, Youle RJ, Colombini M, Bezrukov SM. Bid, but not Bax, regulates VDAC channels. J. Biol. Chem 2004;279:13575-13583. [PubMed: 14729675]

Rostovtseva TK, Bezrukov SM. VDAC regulation: role of cytosolic proteins and mitochondrial lipids. J. Bioenerg. Biomembr 2008;40:163-170. [PubMed: 18654841]

Rowntree RK, Harris A. The phenotypic consequences of CFTR mutations. Ann. Hum. Genet 2003;67:471-485. [PubMed: 12940920]

Sachs F, Morris C. Mechanosensitive ion channels in nonspecialized cells. Rev. Physiol. Biochem. Pharmacol 1998;132:1-78. [PubMed: 9558913]

Sah P, Faber ES. Channels underlying neuronal calcium-activated potassium currents. Prog. Neurobiol 2002;66:345-353. [PubMed: 12015199]

Salkoff L, Butler A, Ferreira G, Santi C, Wei A. High-conductance potassium channels of the SLO family. Nat. Rev. Neurosci 2006;7:921-931. [PubMed: 17115074]

Sampson LJ, Davies LM, Barrett-Jolley R, Standen NB, Dart C. Angiotensin II-activated protein kinase C targets caveolae to inhibit aortic ATP-sensitive potassium channels. Cardiovasc. Res 2007;76:6170. [PubMed: 17582389]

Sampson LJ, Hayabuchi Y, Standen NB, Dart C. Caveolae localize protein kinase A signalling to arterial ATP-sensitive potassium channels. Circ. Res 2004;95:1012-1018. [PubMed: 15499025]

Santi CMD, Butler A, Kuhn J, Wei AD, Salkoff LD. Bovine and mouse SLO3 K ${ }^{+}$channels:evolutionary divergence points to a RCK1 region of critical function. J. Biol. Chem 2009;284:21589-21598. [PubMed: 19473978]

Pongo E, Balla Z, Mubagwa K, Schreiber M, Wei A, Yuan A, Gaut J, Saito M, Salkoff L. Slo3, a novel pH-sensitive $\mathrm{K}^{+}$channel from mammalian spermatocytes. J. Biol. Chem 1998;273:3509-3516. [PubMed: 9452476] 
Schwiebert EM, Egan ME, Hwang TH, Fulmer SB, Allen SS, Cutting GR, Guggino WB. CFTR regulates outwardly rectifying chloride channels through an autocrine mechanism involving ATP. Cell 1995;81:1063-1073. [PubMed: 7541313]

Shennan DB. Swelling-induced taurine transport: relationship with chloride channels, anion-exchangers and other swelling-activated transport pathways. Cell Physiol. Biochem 2008;21:15-28. [PubMed: 18209468]

Shlyonsky VG, Mies F, Sariban-Sohraby S. Epithelial sodium channel activity in detergent-resistant membrane microdomains. Am. J. Physiol. Renal Physiol 2003;284:F182-F188. [PubMed: 12388391]

Shmygol A, Noble K, Wray S. Depletion of membrane cholesterol eliminates the $\mathrm{Ca}^{2+}$-activated component of outward potassium current and decreases membrane capacitance in rat uterine myocytes. J. Physiol 2007;581:445-456. [PubMed: 17331986]

Shoshan-Barmatz V, Israelson A, Brdiczka D, Sheu SS. The voltage-dependent anion channel (VDAC): function in intracellular signalling, cell life and cell death. Curr. Pharm. Des 2006;12:2249-2270. [PubMed: 16787253]

Singh AK, Schultz BD, Katzenellenbogen JA, Price EM, Bridges RJ, Bradbury NA. Estrogen inhibition of cystic fibrosis transmembrane conductance regulator-mediated chloride secretion. J. Pharmacol. Exp. Ther 2000;295:195-204. [PubMed: 10991979]

Sobey CG. Potassium Channel Function in Vascular Disease. Arterioscler Thromb. Vasc. Biol 2001;21:28-38. [PubMed: 11145930]

Sprossmann F, Pankert P, Sausbier U, Wirth A, Zhou XB, Madlung J, Zhao H, Bucurenciu I, Jakob A, Lamkemeyer T, Neuhuber W, Offermanns S, Shipston MJ, Korth M, Nordheim A, Ruth P, Sausbier M. Inducible knockout mutagenesis reveals compensatory mechanisms elicited by constitutive BK channel deficiency in overactive murine bladder. FEBS J 2009;276:1680-1697. [PubMed: 19220851]

Stutzin A, Hoffmann EK. Swelling-activated ion channels: functional regulation in cell-swelling, proliferation and apoptosis. Acta Physiol. (Oxf) 2006;187:27-42. [PubMed: 16734740]

Suzuki M, Morita T, Iwamoto T. Diversity of $\mathrm{Cl}^{-}$channels. Cell Mol. Life Sci 2006;63:12-24. [PubMed: 16314923]

Taverna E, Saba E, Rowe J, Francolini M, Clementi F, Rosa P. Role of Lipid Microdomains in P/Q-type Calcium Channel (Cav2.1) Clustering and Function in Presynaptic Membranes. J. Biol. Chem 2004;279:5127-5134. [PubMed: 14660672]

Thiemann A, Grunder S, Pusch M, Jentsch TJ. A chloride channel widely expressed in epithelial and non-epithelial cells. Nature 1992;356:57-60. [PubMed: 1311421]

Tikku S, Epshtein Y, Collins H, Travis AJ, Rothblat GH, Levitan I. Relationship between Kir2.1/Kir2.3 activity and their distribution between cholesterol-rich and cholesterol-poor membrane domains. Am. J. Physiol. Cell Physiol 2007;293:C440-C450. [PubMed: 17459945]

Torihashi S, Fujimoto T, Trost C, Nakayama S. Calcium oscillation linked to pace-making of interstitial cells of Cajal: requirement of calcium influx and localization of TRP4 in caveolae. J. Biol. Chem 2002;277:19191-19197. [PubMed: 11897792]

Toselli M, Biella G, Taglietti V, Cazzaniga E, Parenti M. Caveolin-1 Expression and Membrane Cholesterol Content Modulate N-Type Calcium Channel Activity in NG108-15 Cells. Biophys. J 2005;89:2443-2457. [PubMed: 16040758]

Toyama K, Wulff H, Chandy KG, Azam P, Raman G, Saito T, Fujiwara Y, Mattson DL, Das S, Melvin JE, Pratt PF, Hatoum OA, Gutterman DD, Harder DR, Miura H. The intermediate-conductance calcium-activated potassium channel $\mathrm{KCa} 3.1$ contributes to atherogenesis in mice and humans. J. Clin. Invest 2008;118:3025. [PubMed: 18688283]

Trouet D, Hermans D, Droogmans G, Nilius B, Eggermont J. Inhibition of Volume-Regulated Anion Channels by Dominant-Negative Caveolin-1. Biochem. Biophys. Res. Comm 2001;284:461. [PubMed: 11394902]

Trouet D, Nilius B, Jacobs A, Remacle C, Droogmans G, Eggermont J. Caveolin-1 modulates the activity of the volume-regulated chloride channel. J. Physiol 1999;520(Pt.1):113-119. [PubMed: 10517805] 
Tsujikawa H, Song Y, Watanabe M, Masumiya H, Gupte SA, Ochi R, Okada T. Cholesterol depletion modulates basal L-type Ca2+ current and abolishes its - adrenergic enhancement in ventricular myocytes. Am. J. Physiol. Heart Circ. Physiol 2008;294:H285-H292. [PubMed: 17982015]

Ullrich N, Caplanusi A, Brone B, Hermans D, Lariviere E, Nilius B, Van Driessche W, Eggermont J. Stimulation by caveolin-1 of the hypotonicity-induced release of taurine and ATP at basolateral, but not apical, membrane of Caco-2 cells. Am. J. Physiol. Cell Physiol 2006;290:C1287-C1296. [PubMed: 16338968]

Vandorpe DH, Shmukler BE, Jiang L, Lim B, Maylie J, Adelman JP, de Franceschi L, Cappellini MD, Brugnara C, Alper SL. cDNA cloning and functional characterization of the mouse $\mathrm{Ca}^{2+}$-gated K + channel, mIK1. Roles in regulatory volume decrease and erythroid differentiation. J. Biol. Chem 1998;273:21542-21553. [PubMed: 9705284]

Vicente R, Villalonga N, Calvo M, Escalada A, Solsona C, Soler C, Tamkun MM, Felipe A. Kv1.5 Association Modifies Kv1.3 Traffic and Membrane Localization. J. Biol. Chem 2008;283:87568764. [PubMed: 18218624]

Vij N, Mazur S, Zeitlin PL. CFTR is a negative regulator of NFkappaB mediated innate immune response. PLoS ONE 2009;4:e4664. [PubMed: 19247502]

Wang D, Wang W, Duan Y, Sun Y, Wang Y, Huang P. Functional coupling of Gs and CFTR is independent of their association with lipid rafts in epithelial cells. Pflugers Arch 2008;456:929938. [PubMed: 18224335]

Wang XL, Ye D, Peterson TE, Cao S, Shah VH, Katusic ZS, Sieck GC, Lee HC. Caveolae targeting and regulation of large conductance $\mathrm{Ca}^{2+}$-activated $\mathrm{K}^{+}$channels in vascular endothelial cells. J. Biol. Chem 2005;280:11656-11664. [PubMed: 15665381]

Weaver AK, Olsen ML, McFerrin MB, Sontheimer H. BK channels are linked to inositol 1,4,5triphosphate receptors via lipid rafts: a novel mechanism for coupling $\left[\mathrm{Ca}^{2+}\right](\mathrm{i})$ to ion channel activation. J. Biol. Chem 2007;282:31558-31568. [PubMed: 17711864]

Wei S-P, Li X-Q, Chou C-F, Liang Y-Y, Peng J-B, Warnock D, Ma H-P. Membrane Tension Modulates the Effects of Apical Cholesterol on the Renal Epithelial Sodium Channel. J. Membrane Biol 220:21.

West A, Blazer-Yost B. Modulation of basal and peptide hormone-stimulated Na transport by membrane cholesterol content in the A6 epithelial cell line. Cell Physiol. Biochem 2005;16:263-270. [PubMed: 16301826]

Wiecha J, Schläger B, Voisard R, Hannekum A, Mattfeldt T, Hombach V. Ca ${ }^{2+}$-activated $\mathrm{K}^{+}$channels in human smooth muscle cells of coronary atherosclerotic plaques and coronary media segments. Basic Res. Cardiol 1997;92:233-239. [PubMed: 9342430]

Wong W, Schlichter LC. Differential Recruitment of Kv1.4 and Kv4.2 to Lipid Rafts by PSD-95. J. Biol. Chem 2004;279:444-452. [PubMed: 14559911]

Wu CC, Su MJ, Chi JF, Chen WJ, Hsu HC, Lee YT. The effect of hypercholesterolemia on the sodium inward currents in cardiac myocyte. J Mol. Cell Cardiol 1995;27:1263-1269. [PubMed: 8531208]

Xia F, Gao X, Kwan E, Lam PPL, Chan L, Sy K, Sheu L, Wheeler MB, Gaisano HY, Tsushima RG. Disruption of Pancreatic \{beta\}-Cell Lipid Rafts Modifies Kv2.1 Channel Gating and Insulin Exocytosis. J. Biol. Chem 2004;279:24685-24691. [PubMed: 15073181]

Xia F, Leung YM, Gaisano G, Gao X, Chen Y, Manning Fox JE, Bhattacharjee A, Wheeler MB, Gaisano HY, Tsushima RG. Targeting of Voltage-Gated $\mathrm{K}^{+}$and $\mathrm{Ca}^{2+}$ Channels and Soluble NEthylmaleimide-Sensitive Factor Attachment Protein Receptor Proteins to Cholesterol-Rich Lipid Rafts in Pancreatic \{alpha\}-Cells: Effects on Glucagon Stimulus-Secretion Coupling. Endocrinology 2007;148:2157-2167. [PubMed: 17303668]

$\mathrm{Xu} \mathrm{X}$, London E. The effect of sterol structure on membrane lipid domains reveals how cholesterol can induce lipid domain formation. Biochemistry 2000;39:843-849. [PubMed: 10653627]

Yarbrough TL, Lu T, Lee H-C, Shibata EF. Localization of Cardiac Sodium Channels in Caveolin-Rich Membrane Domains: Regulation of Sodium Current Amplitude. Circ. Res 2002;90:443-449. [PubMed: 11884374]

Yogi A, Callera GE, Tostes R, Touyz RM. Bradykinin regulates calpain and proinflammatory signalling through TRPM7-sensitive pathways in vascular smooth muscle cells. Am. J. Physiol. Regul. Integr. Comp. Physiol 2009;296:R201-R207. [PubMed: 18799634] 
Yoo D, Flagg TP, Olsen O, Raghuram V, Foskett JK, Welling PA. Assembly and trafficking of a multiprotein ROMK (Kir 1.1) channel complex by PDZ interactions. J. Biol. Chem 2004;279:68636873. [PubMed: 14604981]

Yuan C, O'Connell RJ, Feinberg-Zadek PL, Johnston LJ, Treistman SN. Bilayer thickness modulates the conductance of the BK channel in model membranes. Biophys. J 2004;86:3620-3633. [PubMed: 15189859]

Zerangue N, Schwappach B, Jan YN, Jan LY. A new ER trafficking signal regulates the subunit stoichiometry of plasma membrane K(ATP) channels. Neuron 1999;22:537-548. [PubMed: 10197533]

Zhou Z, Jiang DJ, Jia SJ, Xiao HB, Xiao B, Li YJ. Down-regulation of endogenous nitric oxide synthase inhibitors on endothelial SK3 expression. Vascul. Pharmacol 2007;47:265-271. [PubMed: 17869187]

Zingman LV, Alekseev AE, Hodgson-Zingman DM, Terzic A. ATP-sensitive potassium channels: metabolic sensing and cardioprotection. J. Appl. Physiol 2007;103:1888-1893. [PubMed: 17641217] 

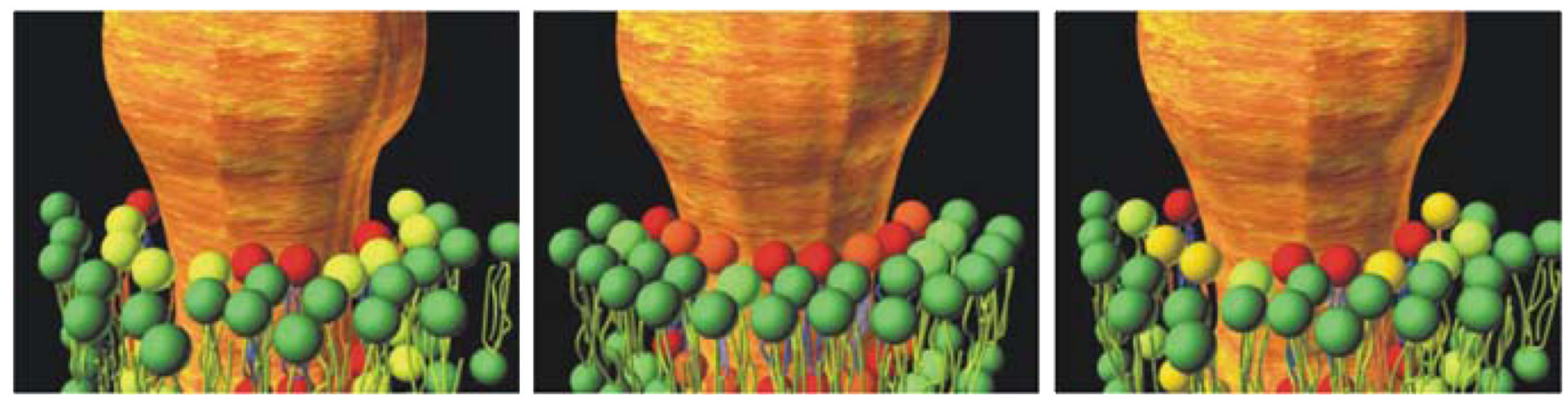

Fig. 19.1.

Regulation of an ion channel by annular lipids (from Barrantes (2004)). The diagram schematically shows a channel protein surrounded by specific lipid molecules that constitute the annular "belt" around the channel. The three panels illustrate the exchange process between the annular lipids and the bulk lipids of the membrane. A cholesterol molecule is proposed to be part of the lipid belt surrounding the channel. (C) Barrantes (2004). Originally published in Brain Research Reviews 47:71-95 

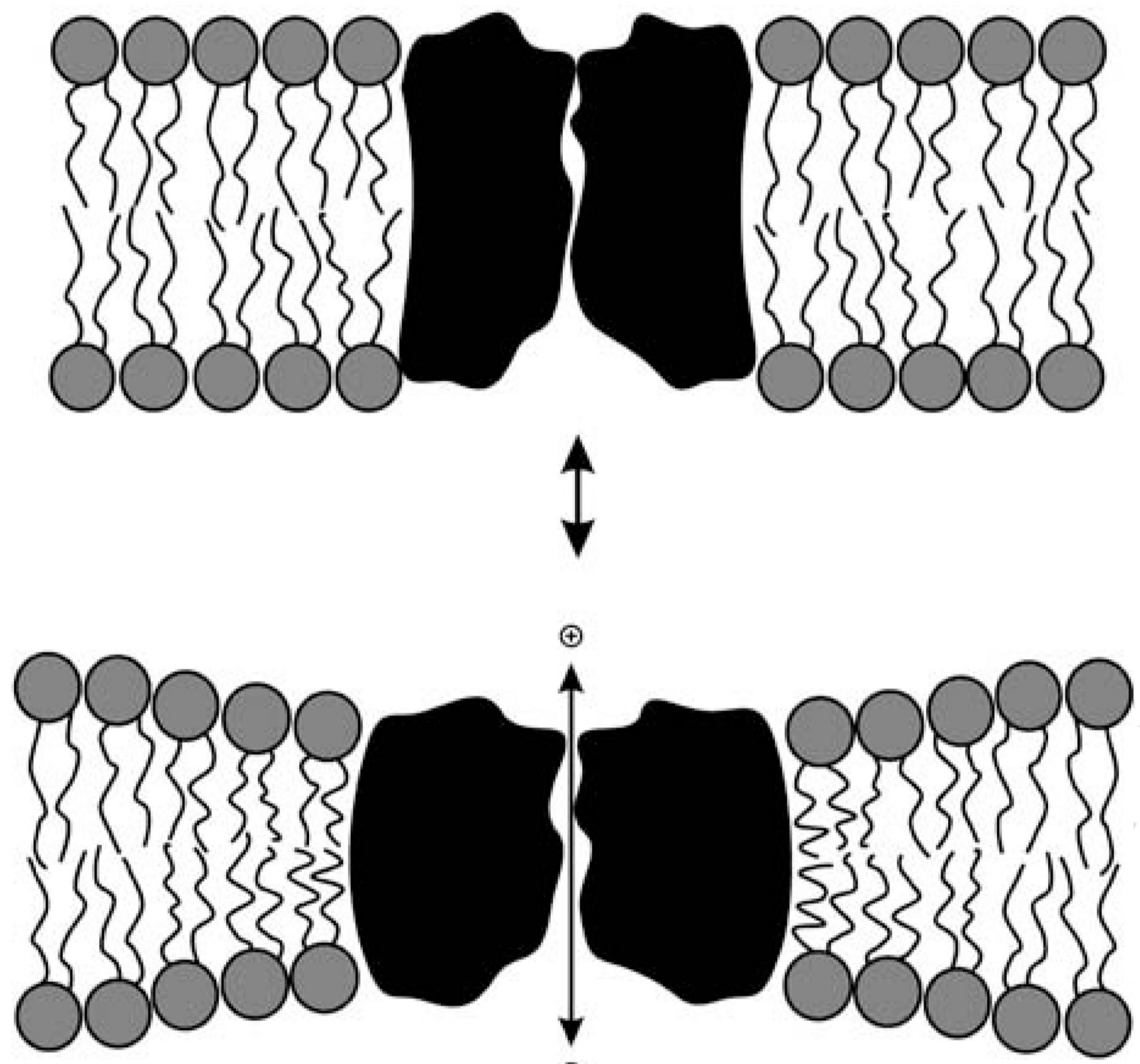

()

Fig. 19.2.

Hydrophobic coupling between channel conformational changes and lipid bilayer deformations. The diagram schematically shows a transition between the closed and the open states of an ion channel that is accompanied with a deformation of the lipid bilayer in the vicinity of the membrane. Membrane deformation involves compression and bending of the membrane leaflets, which is suggested to contribute the energetic cost of the channel opening. In this model, an increase in stiffness of the lipid bilayer is expected to increase the cost of the transition resulting in the inhibition of channel activity. (C) Lundbaek et al. (2004). Originally published in the Journal of General Physiology 123: 599-621 (Reproduced with permission) 
A<smiles>C=C1C[C@]([18O])(P)CCC1(C)C1CCCCCCCCC1</smiles>

B

C
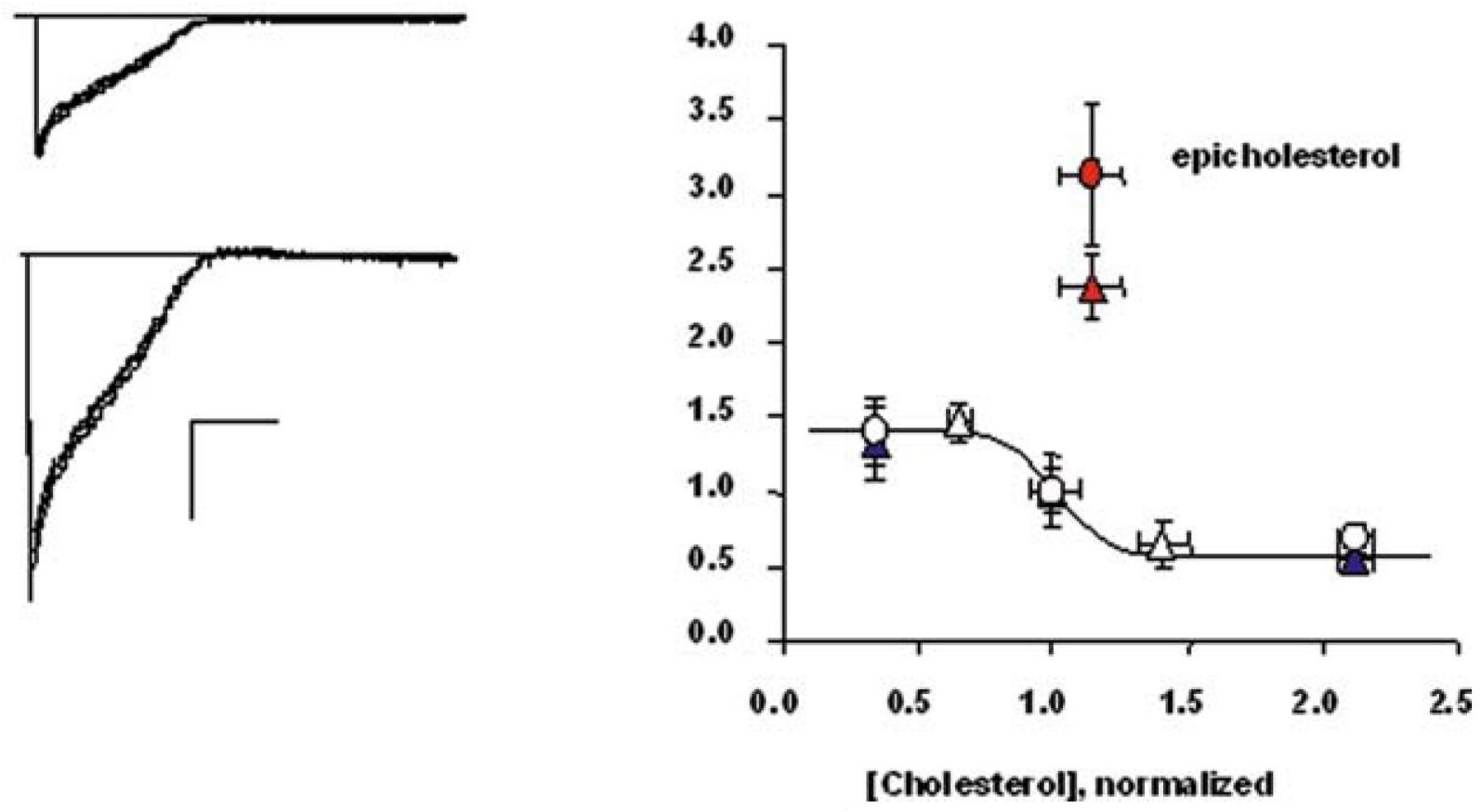

Fig. 19.3.

Chiral analogues of cholesterol have opposite effects on endothelial Kir currents. (A) Structure of cholesterol and epicholesterol. Cholesterol: R1=H, R2=OH; epicholesterol: R1=OH, R2=H. (B) Typical current traces recorded from a cell exposed to M $\beta C D$-epicholesterol and from a control cell. (C) Functional dependence of Kir current density on cholesterol and epicholesterol. Adapted from Romanenko et al. (2002) 

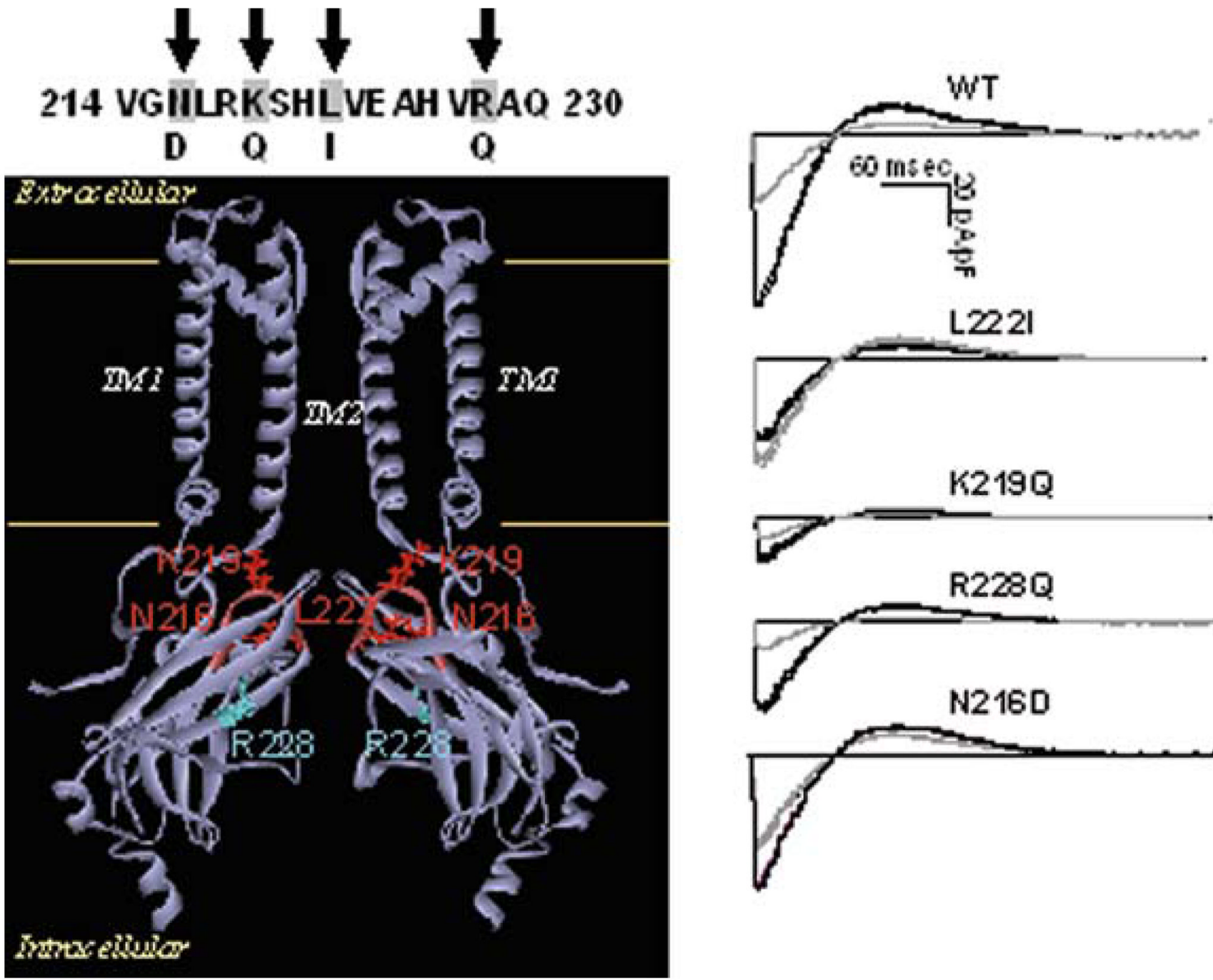

K219Q

Fig. 19.4.

Identification of a cytoplasmic domain critical for the sensitivity of Kir2.1 channels to cholesterol. (A) Sequence of Kir WT with marked PIP $_{2}$-sensitive mutations analyzed for sensitivity to cholesterol and the homology model showing two opposite facing subunits of the channel with the positions of these residues. (B) Typical current traces of Kir2.1-WT, Kir2.1R228Q, Kir2.1-K219Q and Kir2.1-N216D in control cells (grey) and in cells depleted of cholesterol (black) From Epshtein et al. (2009) 

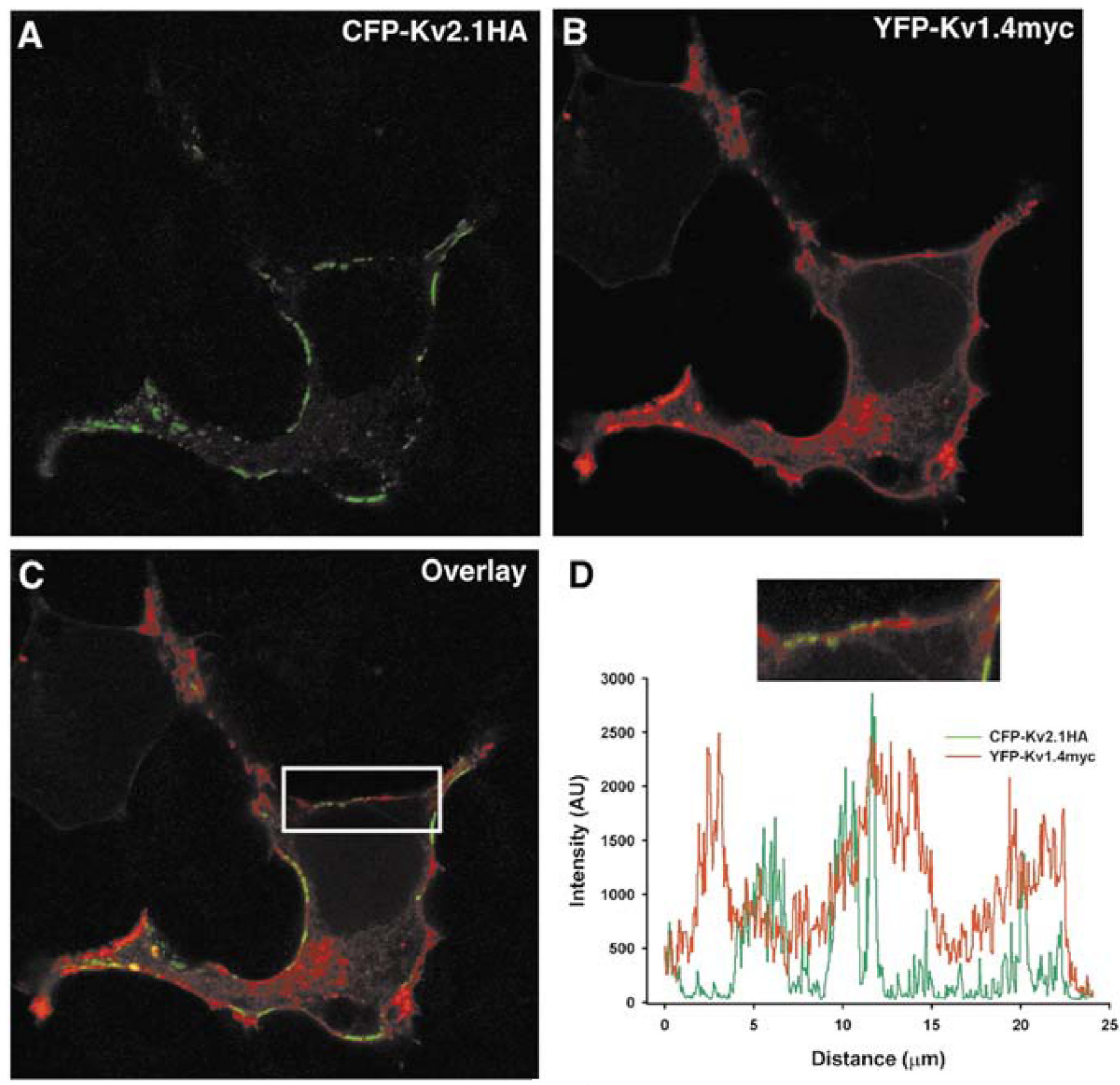

Fig. 19.5.

Partitioning of different of $\mathrm{Kv}$ channels into distinct membrane domains. Lack of colocalization between Kv2.1 and Kv1.4 channels co-expressed in the same cells. (A) Kv2.1-CFP, (B) Kv1.4YFP, (C) the overlay between Kv2.1 and Kv1.4 with Kv2.1-CFP pseudocolored green and Kv1.4-YFP pseudocolored red. (D) Fluorescence intensity profiles of Kv2.1-CFP and Kv1.4YFP showing no or little correlation. From O'Connell and Tamkun (2005), published in the Journal of Cell Science 118: 2155-2166. Reproduced with permission) 
A
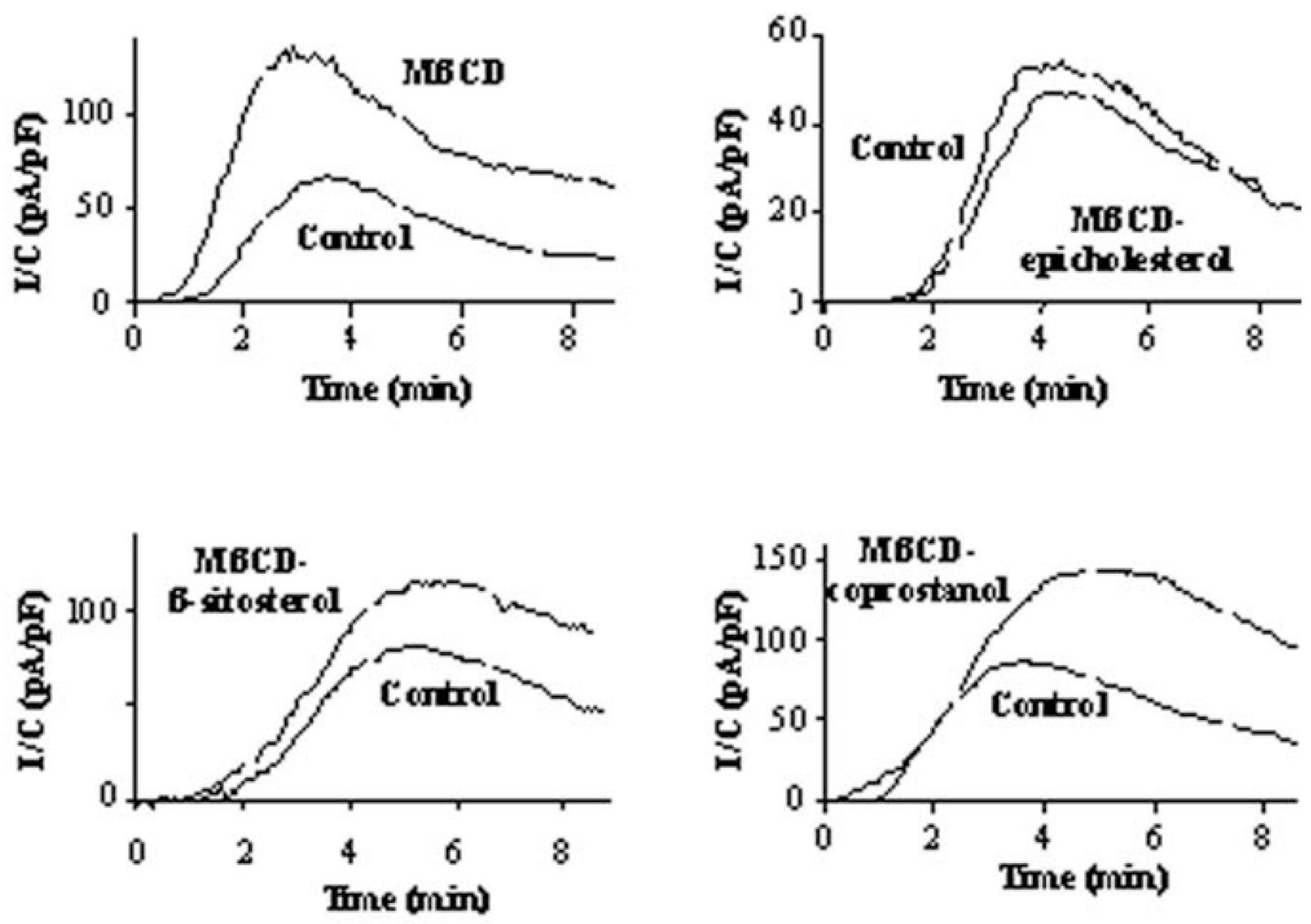

B

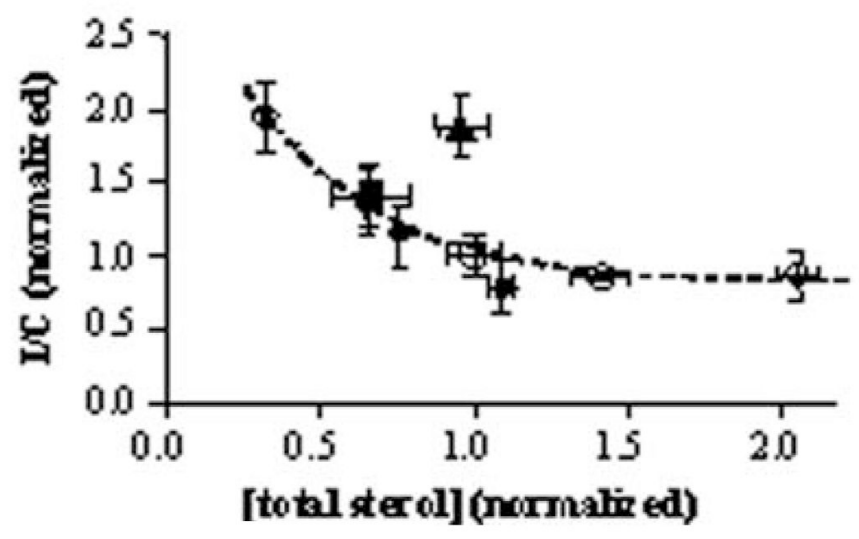

Fig. 19.6.

Differential regulation of GTP $\gamma$ S-activated VRAC by cholesterol depletion and substitution with its analogues. (A) The time-courses of VRAC current densities recorded in cells treated as indicated. (B) Normalized VRAC currents plotted as a function of the total sterol level in cells either depleted of or enriched with cholesterol (open circles) and in the cells, in which endogenous cholesterol was substituted with epicholesterol (diamonds), sitosterol (square), or coprostanol (triangle). In contrast to other two analogues, coprostanol could not substitute for cholesterol in regulation of VRAC, which is consistent with lack of strong effect of coprostanol on the physical properties of the membrane (Adapted from Romanenko et al., 2004b) 